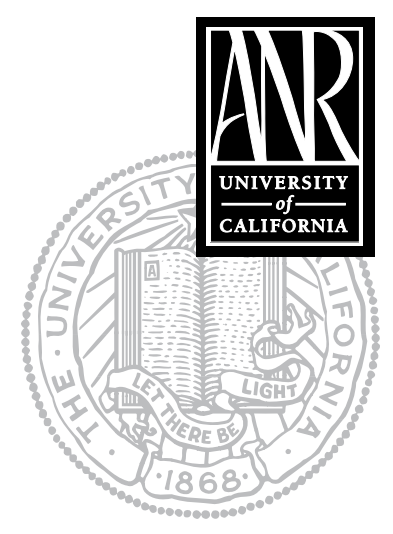

UNIVERSITY OF CALIFORNIA

Division of Agriculture and Natural Resources http://anrcatalog.ucdavis.edu

\title{
Beef Care Practices
}

Technical Editors for the Second Edition: CAROLYN STULL, Veterinary Medicine Extension, University of California, Davis; SHEILA BARRY, UC Cooperative Extension Bay Area Natural Resource Advisor, Santa Clara and Contra Costa Counties; and WAYNE JENSEN, UC Cooperative Extension Livestock Advisor, Santa Barbara and San Luis Obispo Counties

\section{CONTENTS}

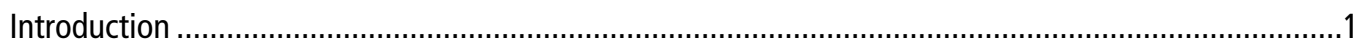

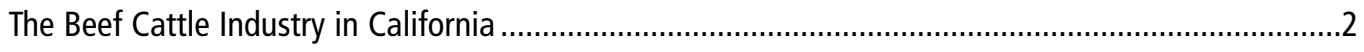

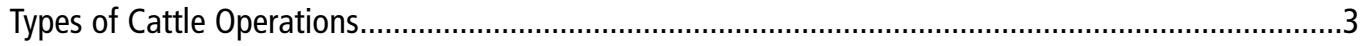

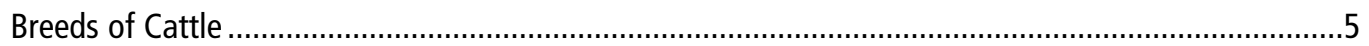

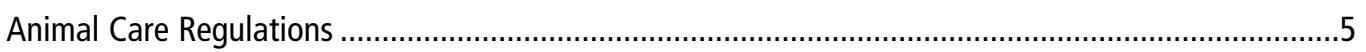

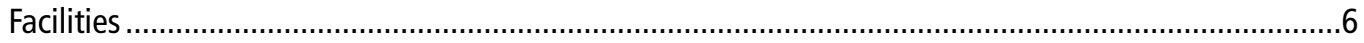

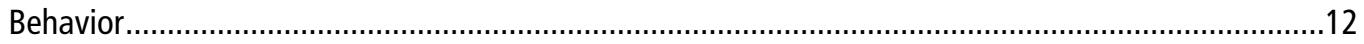

Stress

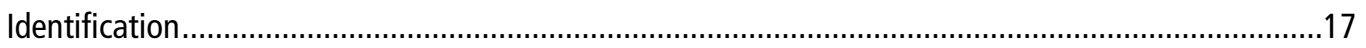

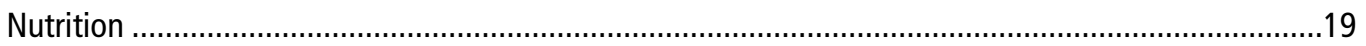

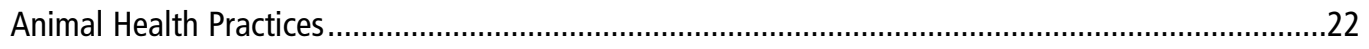

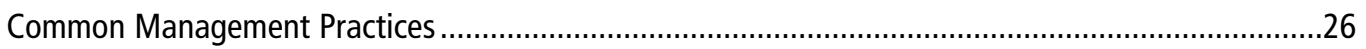

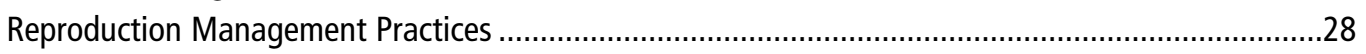

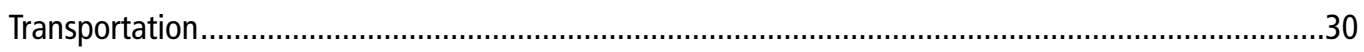

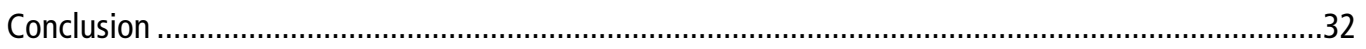

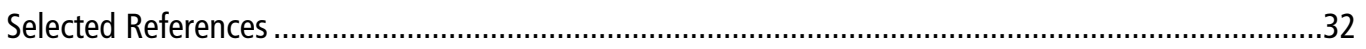

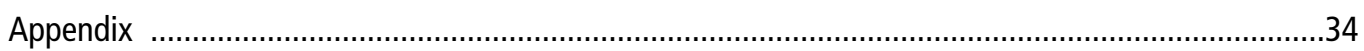

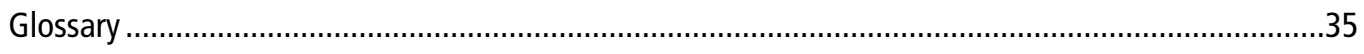

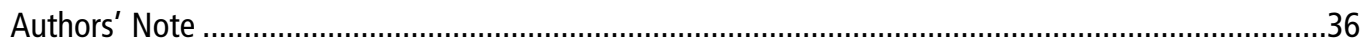

\section{INTRODUCTION}

As recognized in the first edition of Beef Care Practices (Jensen and Oltjen, 1992), the pursuit of an ethically acceptable level of cattle well-being does not limit a producer to one set of husbandry practices. Rather, a variety of practices and conditions may be acceptable, based on individual situations and the specific goals of the beef production system.

Along with the basic information and practices for the care of beef cattle that were described in the earlier edition, this edition covers a number of new issues and opportunities now facing the industry that have the potential to impact animal care practices, and so deserve recognition. These include grass-fed beef and "natural" beef production, a national livestock identification program, and the growing use of prescribed grazing for vegetation management.

In addition, the urbanization of California and the growing recognition that beef cattle can be effectively used as a resource management tool have brought to the forefront conflicts at the urban/rural interface, including nuisance problems and humancattle-dog interactions.

We have written this publication for public land managers, urban neighbors, policy makers, humane officers, and others who have a need or desire to understand factors that affect the well-being of cattle. The information presented here is based on published data, scientific principles, expert opinion, and personal experience with methods and practices for the safe, humane management of cattle for grazing resource management and beef production. 
The goal of this publication is not to set forth or suggest specific guidelines for the management of beef cattle, but rather to explain why, when, and how these practices are used in the management of confined and grazing cattle in California. To best describe these management practices, we must also describe factors that influence their use. These include an understanding of the regions in the state where cattle are raised, the types of beef production systems that growers use, and a basic knowledge of animal science and veterinary medicine as they relate to grazing and confined cattle.

\section{THE BEEF CATTLE INDUSTRY IN CALIFORNIA}

Overall volume. California has the largest agricultural economy in the United States, with diverse agricultural commodities ranging from grapes to milk products. Cattle and calves constitute the sixth-largest commodity in California, with approximately 5.4 million head located on the state's 14,000 beef operations and 2,500 dairy farms. California ranks fourth nationwide in total number of cattle, behind the states of Texas, Kansas, and Nebraska. In 2004, cash receipts for cattle and calves totaled $\$ 1.63$ billion in California. The five California counties reported to have the largest inventory of cattle (beef and dairy) are Tulare, Merced, Imperial, Stanislaus, and Fresno Counties. Beef cattle are raised in every county of California except the City and County of San Francisco. Modoc and Stanislaus Counties lead in number of beef cattle, while Tulare and Merced Counties account for the greatest number of dairy cattle.

Beef consumption in the United States is approximately 66 pounds per person per year, and that number has remained nearly unchanged over the past decade. Beef accounts for approximately 56 percent of the retail red meat sales (beef, lamb, pork, and veal) in the United States. Ground beef and steaks are the most popular beef cuts. Approximately 90 percent of the beef produced in the United States is consumed domestically; the remaining 10 percent is exported worldwide. In California, 1.3 million head of beef with an average live weight of 1,313 pounds were processed during 2004 in federally and state-inspected facilities. The main export markets in 2006 for California beef products were Canada, Mexico, and Hong Kong.

Geographical factors. California is the second-largest state in the contiguous United States and probably the most geographically diverse. It also contains both the highest and lowest elevations in the contiguous United States. California's climate varies from the cool temperatures and 80- to 100-inch annual precipitation levels of Del Norte County to the 2- to 4 -inch annual rainfall and hot, $114^{\circ} \mathrm{F}$ summer days of Imperial County. This geographic diversity and the state's climatic and environmental conditions have allowed the development of a complex livestock production industry.

California covers more than 100 million acres of land, with approximately 40 million acres of range and pasture lands. The rangelands of California are classified as Mediterranean, desert, or intermountain, and are among the most productive in the western United States. Cow-calf, seedstock, stocker, and grass-fed cattle operations use California's range and pasture lands as a primary source of feed for their cattle.

Mediterranean annual rangeland is the predominant range type. This category encompasses all of the rangelands in the Central Valley and the coastal and foothill areas. Actual range forage production in these regions is seasonal, but grazing on green or dry forage occurs throughout the year. Additional Mediterranean grasslands on the north coast are unique because increased rainfall and a moderate climate allows a longer forage production season.

Desert rangelands are found mostly in the state's southern region. A mixture of annual vegetation, perennial grasses, and shrubs makes up the primary forage supply on the desert rangelands. Winter and spring rains support annual plants and grasses, but because rainfall can be erratic, livestock rely on shrubs for feed during dryer periods. 
Intermountain rangelands are found in the northern and eastern portions of the state. Winter dormancy and spring-summer growth dictate a different livestock management scenario for these rangelands. Cattle may graze the lower-elevation forage in the spring and then move to higher-elevation pastures during the summer. In most cases, producers need to harvest a supply of forage in summer and store it for winter feeding. In the fall, cattle may graze crop residues, residual rangelands, or pasture forage. The cattle may be fed hay or transported out of the region to better feeding grounds during the winter.

Much of California's grazing land is privately owned, but numerous federal, state, and local public agencies lease land to cattle operations. Specific missions vary from agency to agency with regard to land use, including open space, wildlife refuge, habitat conservation, watershed, and waste management policies, but their goals for grazing cattle are quite similar. In general, these agencies conduct grazing programs to promote biological diversity and reduce the risk of catastrophic wildfires. Clearly, the goals of livestock and grazing management can be compatible with those of beef production.

\section{TYPES OF CATTLE OPERATIONS}

Cattle operations in California fall into four traditional types: cow-calf, seedstock, stocker, and feedlot operations. In addition there is grass-fed, a newer type of beef cattle operation found in California, and there are programs that certify or acknowledge the use of humane management practices for cattle. These are becoming more popular in the marketing of beef products.

Cow-calf operations maintain a breeding herd of cows, replacement heifers, and bulls. Steer calves and most heifer calves are sold, but some heifers are selected to enter the breeding herd. Calves are sold at weaning or retained as stockers. Unproductive and older cows and bulls also are sold. Climatic and management conditions dictate different calving seasons for different regions of the state. Cow-calf operations are found in most counties of the state. Their cattle use forage as their primary feed component, grazing on annual rangelands, desert, forestlands, and irrigated pastures rather than being confined or housed in feedlots.

Seedstock production is a specialized cow-calf operation sometimes referred to as producing purebred or registered cattle. The goal of seedstock production is to promote genetic improvements in cattle that benefit the entire beef industry. Improvements in purebred cattle are documented through the extensive recording systems maintained by the producer and by breed organizations. Seedstock producers market herd sires and replacement females (including heifers, bred cows, and cow-calf pairs) to cow-calf producers and other seedstock producers. Like cow-calf operations, seedstock producers can be found throughout the state and use forage as their main feed component. Seedstock producers may confine their growing bulls or place them in feedlots to promote growth and demonstrate their ability to convert feed to muscle.

Stocker operations graze weaned steers and heifers on annual rangelands, desert, forest lands, and irrigated pasture throughout the state. In most cases the cattle are purchased after weaning, but they may also be retained by cow-calf producers. They generally graze through one growing season to gain additional weight and size. The time and length of the growing (grazing) season varies with location, rainfall, and temperature. Stocker cattle are normally marketed or transported to feedlots at the end of the season when the quantity or nutritional quality of the forage declines.

Feedlots confine a large number of cattle and feed them to a marketing end point. Cattle fed in feedlots include steers and heifers from cow-calf and stocker operations, unproductive older cows and bulls, and dairy cattle. Dairy cattle may be fed to produce dairy beef or to prepare replacement heifers for milk production. Feedlot facilities are 
designed to meet the feed, water, and care requirements for cattle held in confinement. California has about 20 confined feed operations (feedlots) that feed large numbers of cattle, mostly in the San Joaquin, lower Sacramento, and Imperial Valleys. It should be recognized that the land resources in the United States are insufficient for a forage-based beef supply at the present level of consumer demand. Vast amounts of feed grains and by-products (i.e., rice bran, almond hulls, cottonseed, etc.) are available in this country, and feedlots use these materials to efficiently feed large numbers of cattle. Higher-energy rations greatly reduce the time it takes for cattle to reach market weight. By feeding cattle in feedlots, finished cattle weighing 1,050 to 1,300 pounds can be marketed at 15 to 18 months of age. Cattle fed solely on forage may take 24 to 26 months to reach an end point. In additional to conventional beef, feedlots may produce organic or natural beef, depending on the feed, supplements, and medications provided.

Dairy beef production utilizes male offspring from dairies, which are available in substantial numbers for beef production due to the large dairy industry in California's Central Valley. Unlike calves of beef cattle breeds, which remain with their dams to nurse, most dairy bull calves are removed from their dams shortly after birth and started on a specific feeding program that provides the necessary nutrition and facilities for normal growth. Depending on what facilities the owner provides, these cattle may be raised at first on a forage-based pasture regime and then move on to a feedlot facility to complete their feeding program.

Dairy beef cattle are from the popular Holstein dairy breed. Bull calves of the Holstein breed are castrated and raised as steers to a processing weight of 1,150 to 1,300 pounds at 12 to 14 months of age. Compared to beef industry steers, which are products of the genetics of a vast number of beef breeds, steers produced by the dairy industry are less diverse in their genetics and may be more predictable both in their feedlot performance and their carcass traits. Dairy beef is usually more lean than typical beef products.

Grass-fed beef production refers to a small sector of the beef industry that provides consumers with beef products from cattle that consume only forage products from birth to processing, with the exception of milk consumed prior to weaning. The forage products can consist of annual and perennial grasses, forbs, browse, forage, or stockpiled forages. Hay, haylage, silage, and post-harvest crop residues may also be fed to these cattle, usually during periods of low forage quality or quantity or during inclement weather. They receive no grain or grain products, animal by-products, or plant proteins (i.e., cottonseed or soybean). Some limited vitamin and mineral supplementation is acceptable, however, to provide for the nutritional requirements of the cattle. If a beef producer desires to use "grass-fed" as a marketing claim in order to distinguish his or her products in the retail market, the U.S. Department of Agriculture (USDA) has developed a voluntary verification program that includes an annual audit of the production process in order to allow the use of a "USDA Process Verified" label.

Humane programs focused on the care and treatment of animals in a beef operation range from the voluntary establishment of a minimum set of standards developed by a single beef operation to programs of recommended guidelines developed by the industry and sometimes incorporated into a quality-assurance program. Additionally, several non-profit animal protection organizations have developed certifying humane programs requiring an annual third-party audit. Often, beef products from these humane-certified programs carry a label to identify them to consumers in the market. Welfare standards for these programs may include topics such as feeding, housing, facility maintenance, training of management and employees, health programs, handling methods, sanitation, transportation methods, and euthanasia plans. 


\section{BREEDS OF CATTLE}

There are 275 recognized cattle breeds in the world. More than 40 breeds are raised in California, including the major dairy cattle breeds. A producer's choice of breed or breeds is based on many factors, including local environmental characteristics, breed characteristics, availability of labor resources, market demand, and the producer's personal preference. Most cattle produced in California are crossbred to combine or match desirable characteristics from two or more breeds. A producer can use crossbreeding to develop animals with characteristics that are optimally suited for production in a particular region.

Five to ten breeds dominate beef production in California. These include Angus, Hereford, Charolais, Brahman, Gelbvieh, and Limousin. Breeds differ in many characteristics, and producers commonly cross several breeds to enhance certain characteristics. Simple observable traits may include hair and skin color or the presence of horns or absence of horns (polled breeds). Differences in production traits such as reproductive performance, growth rate, milk production, disease resistance, and carcass merit are found within a breed as well as between breeds.

\section{ANIMAL CARE REGULATIONS}

California animal laws concerning the care and handling of beef cattle focus mainly on the prevention of cruelty, abuse, and neglect. These include the following:

Penal Code 597: “. . . every person who overdrives, overloads, drives when overloaded, overworks, tortures, torments, deprives of necessary sustenance, drink or shelter, cruelly beats, mutilates, or cruelly kills an animal . . is guilty of an offense punishable as a misdemeanor or felony."

Penal Code 599f: "(a) No slaughter house that is not inspected by the United States Department of Agriculture, stockyard, or auction shall buy, sell, or receive a nonambulatory animal.

"(b) No slaughterhouse, stockyard, auction, market agency, or dealer shall hold a nonambulatory animal without taking immediate action to humanely euthanize the animal or remove the animal from the premise.

"(c) While in transit or on the premise of the stockyard, auction, market agency, dealer, or slaughterhouse, a nonambulatory animal may not be dragged at any time, or pushed with equipment at any time, but shall be moved with a sling or on a stoneboat or other sled-like device or wheeled conveyance.

"(d) A violation of this section is a misdemeanor."

Food and Agriculture Code 16908: "Confinement of Animals in Truck Transit: Rest, Water, and Feeding: Storm or Accident. It is unlawful for any person that owns or operates any motor truck and trailer, or semi-trailer, to confine or permit to be confined, in such vehicle; any animal for a longer period than 28 consecutive hours from the time the animal was last fed and watered. Upon the written request of the owner or person in charge of the animal, the period of confinement may be extended to 36 hours. Before the expiration of the permissible period of confinement, the animal shall be unloaded in a humane manner by means of a chute or tailgate of sufficient size into properly equipped pens for rest, water, and feeding for a period of at least five consecutive hours. The failure of a person to feed and water an animal within the time limit prescribed by this section is not a violation of this section if the feeding and watering of the animal is prevented by storm or other accidental or unavoidable causes which could not be anticipated or avoided by the exercise of diligence and foresight." 


\section{FACILITIES}

\section{Confined or Feedlot Cattle}

Confined housing or feedlots require a higher level of management and facilities than are required by grazing operations. The basic needs for handling and processing cattle are similar, but additional facilities are required to allow a confined operation to accommodate the needs of large numbers of cattle in a comparatively small area during an extended feeding period. The space required by cattle in unsurfaced (earth) pens depends on the climate and soil type at the facility site. In dry climates, 75 square feet of space per animal is usually adequate, but wet, muddy climates may require 300 square feet per animal. Feedlots are typically built to accommodate 100 to 300 cattle in each pen, but some use smaller pens.

Feed bunk space should be designed to allow all animals in the pen to consume feed with minimal conflict between individuals. If feed is always available, an allowance of 6 to 10 inches along the length of the bunk for each animal is adequate. If the cattle are limit-fed twice a day, sufficient space must be provided to allow all animals in the pen to stand at the bunk simultaneously as they are fed. Depending on the animals' size, 20 to 30 inches per animal is usually adequate. A sloped, 6- to 8-foot concrete apron adjacent to and behind the bunk where the cattle can stand while they feed may reduce the problem of muddy areas near the feed bunk. When they eat at the bunk, cattle should stand on a slight incline (with the front feet about 4 inches higher than the rear feet).

Pen comfort. Production losses can occur if the space provided per animal is not adequate to allow proper social spacing. Many variables influence social space, including type of floor, availability of water, feeder space, pen mates, degree of health or sickness, shape of pen, kinship among pen mates, and environmental factors such as prevalence of flies and mud, availability of shade, and temperature. Muddy pens and extremely hot or cold temperatures may be detrimental to the cattle's well-being. In areas with more than 6 inches of annual rainfall, a 3 percent slope should be sufficient to reduce muddy surfaces. However, excessive slopes will accentuate surface runoff and the potential for erosion. State and federal laws regulate the amount of feedlot manure and surface runoff to protect against groundwater pollution. In California, Regional Water Quality Control Boards regulate drainage from confined animal operations.

Manure management for feedlot cattle is an important consideration for maintaining the comfort of cattle, minimizing the spread of pathogens and parasites, protecting water quality, and maintaining an environmentally sound enterprise. Beef cattle weighing 1,000 pounds excrete approximately 60 to 90 pounds of manure a day, with a water content of about 90 percent. Since confined facilities and feedlots house a large number of animals in a relatively limited area, such facilities should be designed to adequately collect manure from the pens, store it properly, and utilize or dispose of it. Some facilities may be required to secure a permit from the state water quality agency or the U.S. Environmental Protection Agency.

Lighting. Lights can cause stress in a confinement situation. If the cattle operation requires lighting so the cattle can be worked before dawn or for security purposes, the light should be evenly diffused. It should not create harsh shadows and bright spots or be directed into the eyes of the cattle for prolonged periods.

Heat stress. Shade is perhaps the single most studied environmental modification for reduction of heat stress in cattle, followed by water sprinklers and other measures such as adjustments in stocking density. Shade and water sprinklers directly reduce the impact of heat stress on cattle. Shade reduces the radiant heat load and allows cattle to dissipate heat, by conduction, to the ground. Unshaded cattle have a high radiant heat 
load and cannot dissipate heat by conduction because the ground temperature often exceeds the animals' body temperature. Confined housing facilities in areas with more than 90 days per year of temperatures greater than $100^{\circ} \mathrm{F}$ should have shades in the pens. Under hot conditions, cattle in confinement require 25 to 40 square feet of shade per head. Shade structures should be about 12 feet high. To ensure the availability of shade throughout the day, the shades should be built in a north-south orientation and offset toward the west.

Water sprinkling is a means of inducing evaporative cooling for animals as well as a mitigation measure for particulate matter or dust control. When a large water droplet comes in contact with an animal's hair coat, it penetrates through the hair and deposits on the skin. The moisture collects body heat and removes it from the animal through direct evaporation and, to a lesser extent, convection. This effect may be achieved using sprinklers with a capacity of 10 to $20 \mathrm{~L}$ per minute ( 2.6 to $5.3 \mathrm{gal} / \mathrm{min}$ ) of water that covers a circular area approximately 20 to $30 \mathrm{~m}$ ( 22 to $33 \mathrm{yd})$ in diameter. Ideally, all sprinklers will come on for a set number of minutes within each hour (e.g., 5 to 10 minutes per hour) and operate throughout the hottest part of the day. This intermittent sprinkling allows time for the water that accumulates on the animals' skin to evaporate, taking evaporative heat away from the animals. High relative humidity decreases the effectiveness of evaporative cooling from the skin's surface. Fine mist applications have an affect similar to that of relative humidity and unlike that of large water droplets, creating an insulating barrier between the animal's skin and its outer hair. Fine mist actually traps body heat, leading to an increase in the likelihood of heat stress.

Costs associated with shade structures and sprinkling systems must figure into the producer's evaluations when considering options. Shade structure installation is a one-time cost with little continuing maintenance cost. The economic benefits of shade accrue over time as a result of improvements in cattle performance. The application of water to a corral is both a one-time cost (for pipes, sprinklers, etc.) and an ongoing cost (for water and system maintenance), and in regions where water is a limited resource or relative humidity is high, its application is not feasible. Water applications do have the added benefit of reducing dust.

Air quality. Animal feeding operations such as feedlots emit ammonia and particulate matter (PM) into the atmosphere. According to the U.S. Environmental Protection Agency, the largest contribution of ammonia emissions in the United States comes from livestock, which produce an estimated 50 to 70 percent of total such emissions. Exposure to ammonia can be a respiratory health hazard. Ammonia has irritant properties, and when combined with water it can injure and burn the respiratory tract. Ammonia can also alter the uptake of oxygen by hemoglobin, leading to decreased metabolic function. Prolonged exposure to high levels of ammonia can cause death. Ammonia emissions can be reduced by manipulating the composition of the herd's diet, scraping the pens to remove manure, and maintaining the moisture level of the pen's ground surface at less than 40 percent.

The peak periods of PM emissions in beef and dairy cattle operations occur around dusk and dawn in confined housing conditions, the most active time of day for cattle. These emissions occur when cattle pulverize the dry manure pack with their hooves, expelling particles into the air. Some of the airborne particles can carry infectious agents or microbes into the cattle's lung tissues and even into their bloodstream via respiration. Particles smaller than $10 \mu \mathrm{m}$ in diameter $\left(\mathrm{PM}_{10}\right)$ are small enough to enter the respiratory system, while particles smaller than $2.5 \mu \mathrm{m}$ in diameter $\left(\mathrm{PM}_{2.5}\right)$ can enter the lungs' alveoli, introducing infectious agents into the respiratory system. Particles smaller than $1 \mu \mathrm{m}$ in diameter can diffuse into the bloodstream from the respiratory system. Water sprinkling reduces PM emissions from the pens. For example, feedlot operators in Imperial County are mandated to maintain moisture levels in their pens of at least 20 percent in order to keep PM emissions low. 


\section{Grazing Cattle}

Although a minimum space can be prescribed for cattle in confinement, such as those residing in a feedlot, the amount of land required for grazing animals varies substantially based on a number of physical factors including (but not limited to) forage production, slope, access to water, available supplements, type of cattle (i.e., stockers, cows and calves, or bulls), and the extent of grazing desired. The number of head a specific pasture can accommodate is known as its carrying capacity. The carrying capacity for an irrigated pasture may range from 1 to 2 acres per animal unit ( 1 animal unit or "AU" is the equivalent of a 1000-pound cow), whereas the carrying capacity for a dryland pasture in California can range from 5 to 100 acres per AU.

To determine the desired level of utilization on dryland pastures, growers often refer to measurements of residual dry matter (RDM) made prior to the germinating rains in autumn. RDM is an estimate of the amount of plant material remaining above the ground prior to the next growing season. An adequate level of RDM protects soil from erosion and limits the establishment of undesirable plant species. The amount of RDM also influences the following year's plant composition.

Fencing. Fence statutes are intended to protect livestock, people, and property from damage that could be caused by livestock. These laws take two forms: open range and closed range. In California, local county governments determine whether the range will be considered open or closed. While most California counties have closed range laws, the counties of Modoc, Lassen, and Siskiyou, as well as areas of Shasta and Kern, have open-range areas devoted to grazing (California Food and Agricultural Code, Section 17123). In closed-range areas, it is the cattle owner's responsibility to keep cattle enclosed. However, if the cattle break through a fence, the degree of the owner's liability is usually based on normal husbandry practices along with the consideration of a what constitutes a "lawful fence." The California Food and Agricultural Code (Section 17121) describes a "lawful fence" as "any fence which is good, strong, substantial, and sufficient to prevent the ingress and egress of livestock. No wire fence is a good and substantial fence within the meaning of this article unless it has three tightly stretched barbed wires securely fastened to posts of reasonable strength, firmly set in the ground not more than one rod apart, one of which wires shall be at least four feet above the surface of the ground. Any kind of wire or other fence of height, strength, and capacity equal to or greater than the wire fence herein described is a good and substantial fence within the meaning of this article. The term 'lawful fence' includes cattle guards of such width, depth, rail spacing, and construction as will effectively turn livestock."

A few California counties have open-range laws. In an open-range area animals are allowed to roam and neighbors are responsible for protecting their property by erecting fences to keep cattle out. Property owners who choose not to erect a fence in an openrange area cannot legally claim compensation for damage caused by the roaming cattle.

Factors for selecting the type of fence include its affordability, maintenance requirements, durability, and effectiveness. Fencing types vary from physical barriers such as barbed wire and board fences to psychological barriers such as electrified poly wire. A high-tensile electric wire fences combines both types of barrier. Perimeter fences should be "lawful fences," while interior fences used to control livestock movements or distribution may be built to looser standards depending on their intended use and the disposition of the livestock. 
Table 1. Approximate total daily water intake of beef cattle

\begin{tabular}{|c|c|c|c|c|c|c|}
\hline & \multicolumn{6}{|c|}{ Air temperature } \\
\hline & $40^{\circ} \mathrm{F}$ & $50^{\circ} \mathrm{F}$ & $60^{\circ} \mathrm{F}$ & $70^{\circ} \mathrm{F}$ & $80^{\circ} \mathrm{F}$ & $90^{\circ} \mathrm{F}$ \\
\hline \multicolumn{7}{|c|}{ Growing heifers, steers, and bulls } \\
\hline Weight & \multicolumn{6}{|c|}{ Daily water intake (gal) } \\
\hline $400 \mathrm{lb}$ & 4.0 & 4.3 & 5.0 & 5.8 & 6.7 & 9.5 \\
\hline $600 \mathrm{lb}$ & 5.3 & 5.8 & 6.6 & 7.8 & 8.9 & 12.7 \\
\hline $800 \mathrm{lb}$ & 6.3 & 6.8 & 7.9 & 9.2 & 10.6 & 15.0 \\
\hline \multicolumn{7}{|c|}{ Finishing cattle } \\
\hline Weight & \multicolumn{6}{|c|}{ Daily water intake (gal) } \\
\hline $600 \mathrm{lb}$ & 6.0 & 6.5 & 7.4 & 8.7 & 10.0 & 14.3 \\
\hline $800 \mathrm{lb}$ & 7.3 & 7.9 & 9.1 & 10.7 & 12.3 & 17.4 \\
\hline $1,000 \mathrm{lb}$ & 8.7 & 9.4 & 10.8 & 12.6 & 14.5 & 20.6 \\
\hline
\end{tabular}

\section{Water Availability}

Confined or grazed cattle should always have access to clean, fresh water. Water is very important for their feed intake and overall health. It must be available in sufficient quality and quantity to allow cattle ready access without competition (table 1). Insufficient space for animals to drink, low flow rates, low storage capacity, high temperatures, high mineral content, or unfamiliar taste can discourage the animals' water consumption to the point that their feed intake is reduced.

Two feet of space at the water tank edge should be provided for every 25 head of cattle drinking throughout the day; if the entire herd drinks at once, though, two feet of tank edge must be provided per head. Muddy conditions near water tanks should be avoided or kept to a minimum. Each water trough should have a concrete apron and a drain to reduce muddy conditions in the pen. Water should be of an acceptable temperature for the cattle, and in order to achieve this the pipes leading to the trough may have to be buried or placed out of the sun. Water troughs in northern latitudes or at higher elevations should be equipped with water heaters to prevent the water from freezing; alternatively, the producer can establish a routine of breaking ice to ensure the availability of liquid water.

Watering systems for confined housing facilities require a tank capacity of at least 50 percent of a 1-day water supply and the system should be able to replenish a full day's supply within 8 hours. In grazing systems, the combined capacity of all water tanks should provide at least a 1-day supply for the entire herd. Since grazing cattle usually drink together as a group within a short period of time once or twice per day, the watering system (pump, pipe diameter, reservoirs, etc.) should be sufficient to replenish the entire 1-day supply in 4 hours. Good-quality drinking water is not only important for the cattle's well being; it is also an important grazing management tool. In fact, it is the most important grazing management tool for controlling livestock distribution. Cattle distribution relative to water sources depends on a variety of factors, including type of cattle, slope of the terrain, availability of shade, and vegetation, but cattle generally prefer to stay within 600 to 700 feet of water. When that distance is 
less than 700 feet, the cattle will usually drink individually, but when distances exceed 700 to 1000 feet cattle will travel as a social group to the water source. The general rule for the maximum distance for livestock to travel to water is 0.5 mile for rough, hilly environments and 2 miles for smooth, flat rangelands.

\section{Handling Facilities}

Handling facilities constitute an essential part of any cattle operation. A well-designed and maintained handling facility can include a holding chute, working chute, crowding pen, holding pen(s), corrals, scales, and a loading chute. Even if the grazing operation's primary purpose is vegetation management, handling facilities are necessary for personnel to gather and receive animals, provide preventive health treatments, and treat sick animals. Well-built, functional facilities contribute to easy, safe, and efficient handling of the cattle and safe conditions for the livestock handler. Private insurance carriers, numerous state laws, and CAL-OSHA also mandate a safe working environment for the personnel who handle the cattle.

Facilities should be designed to accommodate the type and size of cattle being processed or confined. The number of cattle using the facility and its local environment are also important considerations in facility design. For example, if the facility is normally used early in the mornings, it should be constructed so the flow pattern will

Table 2. Recommended space allowance (square feet per animal) for holding areas

\begin{tabular}{lccc} 
& \multicolumn{3}{c}{ Area per animal of this weight: } \\
\cline { 2 - 4 } Holding period & Under $600 \mathrm{lb}$ & $600-1,200 \mathrm{lb}$ & 0ver 1,200 lb \\
\hline Processed immediately & 14 sq. $\mathrm{ft}$ & 17 sq. $\mathrm{ft}$ & 20 sq. $\mathrm{ft}$ \\
Held overnight & 45 sq. ft & 50 sq. $\mathrm{ft}$ & 60 sq. $\mathrm{ft}$ \\
\hline
\end{tabular}

not face the cattle to the east or southeast. Cattle facing into the sun may balk as they move through a handling facility.

Materials used in corral and pen construction can vary greatly. Consideration of environmental conditions is important: for example, in desert regions, wooden fences that restrict air flow may increase heat stress for the cattle. In colder climates, confined animals may benefit if there is protection from wind, rain, or snow.

The design of pens, alleys, and chutes should be as simple as possible to create an efficient flow pattern when moving the cattle. Cattle tend to circle and will follow the lead animal, so they should be allowed to see animals ahead. While open-sided chutes can be used satisfactorily by competent personnel, curved solid chutes are more efficient. Cattle will stand more quietly and move more easily through a single-file chute when their peripheral vision is restricted. Solid sides prevent the animals from observing people, vehicles, dogs, and other external stimuli or distractions with their wide-angle vision.

One of the most common flaws in holding pen design is to use existing corrals that are too large for the purpose. Cattle being moved or sorted by a handler in a large area can easily turn around or move in the wrong direction. An appropriate-sized holding pen will facilitate the efficient and quiet handling of the cattle with a minimum of agitation, excitement, and stress (table 2). Sorting is best performed using a lane that opens from a holding area. Smaller pens are needed for use as hospital pens for sick or injured cattle and to quarantine any newly arrived animals. Ideally, each hospital pen should have its own water source that is not shared between pens. 


\section{Restraint Equipment}

Animal restraint is necessary for safe performance of some management practices involved in beef production. The restraint tools must quickly and easily restrain the animal without injury and must be safe for the handler. The tools should allow the animal to be restrained securely during the procedure and then easily and quickly released when the procedure is finished. Depending on the type of facility, restraints may include ropes or mechanical devices. The mechanical device used depends on the size of the animal and the number of animals to be handled.

Calf tables are used by some cow-calf operators to restrain calves; others prefer to use ropes for restraint. As animals grow larger, most producers use squeeze chutes of various designs to restrain their cattle. The frequency of use and the number of cattle, along with operator considerations, determine whether a manual or hydraulic squeeze chute will be used. Cattle tend to rush when they exit a squeeze chute, so a slip-resistant surface should be provided to prevent injury to the cattle. Regardless of which restraining device is used to restrain cattle, it should only be used by experienced or trained personnel who know how to prevent injury or choking of the animal while it is being restrained.

\section{Animal Movement}

Producers occasionally need to move their cattle. Since relocation may be stressful, handlers should take measures to minimize the potential for stress and excitement during the move. Cattle should be moved slowly and not forced to run. Depending on the situation and environmental conditions, the movement of cattle may be controlled by using handlers on foot or on horseback or using mechanized means.

Various handling aids-including flags, plastic paddles, sorting sticks and possibly whips or backslappers-may be used, with a minimum of force, in order to initiate or continue the movement of cattle. The decision process for selecting handling aids should include consideration for minimizing the animals' stress by using the least amount of force necessary to both control the animal and ensure the safety of herd mates and handlers.

Trained dogs or horses with riders often assist in the handling and moving of livestock, but to prevent stress or injury to cattle any working stock dogs must be properly trained. Untrained and uncontrollable dogs can develop aggressive, predatory behaviors, such as barking, stalking with possible subsequent attacking, and biting at the cattle, any of which is stressful to the cattle and can cause injury to both the cattle and the dog.

Cattle moving through a chute may balk or lie down. Cattle that balk take longer to handle, accumulate more stress, are more prone to hurting themselves, can cause injury to other animals, and can injure personnel handling the cattle. These risks may be reduced with the judicious use of a hand-held electric prod to keep the cattle moving forward. The prod should be used as a last resort only on cattle that balk or otherwise impede movements in the chute during processing or loading and unloading. Electric prods generally are not useful when moving cattle in alleys or within pens. For the most effective use in movement of livestock, the prongs of the prod need only make light contact with the skin of the animal. The electric prod should not be used to poke or probe the cattle. 


\section{Auctions and Sale Facilities}

Auctions and sales yards are components of the commercial channels available for marketing cattle. These facilities are inherently stressful to cattle due to a combination of factors such as novel environment, unfamiliar noises and smells, mixing of animals, and changes in diet. Some of the cattle arriving at a sales yard are destined for slaughter facilities while other cattle are transported from the sales facility to stocker, feedlot, or other facilities.

The auction and sale facilities should be safely designed and maintained to prevent animal injuries while unloading, loading, and handling them. Animals should be handled humanely and carefully since stressful, rough, or otherwise improper handling may produce stress, pain, bruising, and other injuries that will diminish the animals' future productivity or meat quality. Additionally, incidents concerning the improper or careless handling of an animal may reflective negatively on the entire industry in the public's view. Animals should be penned in groups according to species, size, age, and other physical characteristics, such as the presence of horns on cattle. Overcrowding in pens may contribute to injuries and stress. Animals that appear sick, lethargic, distressed, lame, or injured should be separated from the rest and appropriately treated. Any terminally ill or gravely injured animal should be euthanized immediately by trained personnel.

Facilities at auctions and sales yards should provide protection against extreme weather conditions and should be properly ventilated. The walkways and alleys should have non-slip surfaces that facilitate safe movement of animals. In general, feed and water should not be withheld for more than 24 hours at a time, and that includes the cumulative time for transport to and residing at the sales facility. The 24-hour limit is appropriate for mature cattle; use a shorter period for younger cattle. Preferably, water should be available in the pens at all times.

\section{BEHAVIOR}

The observation and assessment of behavior patterns in cattle is important in determining their health, minimizing the incidence of stressful or painful situations, assisting in the improvement of production practices, and providing for the well-being of individual animals. Understanding and recognition of typical and atypical cattle behavior are critical to efforts to design livestock facilities, minimize animal stress and injury, and assure the safe and efficient interaction of handlers with cattle.

Senses. The basic senses help cattle perceive their environment or situation and provide them with information that will govern their behavior. Cattle have wide-angle vision, with a field of vision of nearly $360^{\circ}$ for both eyes combined. This is important to keep in mind when handlers are approaching cattle. Cattle possess relatively poor depth perception, but they can distinguish between most colors. They can detect motion easily and rely on their vision to identify herd mates or receive signals conveyed by the body postures of herd mates. In cattle, positions and motions of the head and body can indicate alarm, threat, or submission.

Cattle can move their ears to improve the acuity of hearing. Information on possible threats or the identification of an approaching animal (whether threatening or nonthreatening) can be communicated between cattle through vocalizations and hearing. A sudden or unexpected loud noise may startle animals and this is an important consideration when personnel are handling or confining cattle. Cattle also are often frightened by unfamiliar noises associated with novel events such as those involved in handling or transport. However, cattle may also become adapted to loud noises in their environment, such as trains that pass in the near vicinity or low-flying planes. This type of habituation to repetitive noises has been shown in scientific trials to develop in cattle over a 5-day period. 
Smell and taste are significant in establishing feed preferences, determining the reproductive status of females, identifying territory, and bonding between a cow and her calf. Tactile stimulation (touching) may convey signals of heat, cold, pressure, or pain that signal the cattle's central nervous system to trigger appropriate physiological and behavior changes. Cattle may change or alter their posture to conserve or avoid heat, and a painful stimulus can cause the animal to flee its immediate environment.

Types of behaviors. Instinctive or innate behaviors have evolved to help animals survive and reproduce, given an appropriate environment. Examples of innate behaviors include the receptive stance of a female at mating or the initial nursing behavior of a newborn calf. Behaviors that result from previous experience are learned behaviors. A learned behavior requires that the animal use its memory and store information over time. When cattle start walking toward the feed bunk at the sound of a tractor, that is a learned behavior. A behavior also can be altered as an animal becomes accustomed to a harmless stimulus, such as when a calf shows little or no behavioral response to the sound of a noisy tractor. Some behaviors can be changed with some effort; others, such as sexual behaviors, are more difficult to alter.

Cattle possess a natural following tendency. This is especially evident when a herd is threatened or aroused. Following behavior may be dependent on an animal's ability to maintain visual contact with other animals. An animal's potential flight zone may determine how close a handler can approach the animal. The flight zone is an area surrounding an individual animal, and it moves with the animal. Following behavior and flight zone are important concepts for employees to keep in mind in order to minimize stress while handling and moving animals or when designing facilities. Usually it is less stressful to move cattle in small groups, or even as a pair, rather than as individuals.

Herd interactions. All cattle are herd animals and behave according to herd instincts and herd-based social interactions. Cattle prefer to remain with a herd rather than individually penned or otherwise isolated. A dominance ranking or "pecking order" establishes the hierarchy within each herd. Dominance is a learned behavior that establishes a predictable relationship between a pair of animals, where one animal is consistently submissive to the other. When new herd mates are introduced into an established herd, the cattle will initiate a reorganization of the dominance ranking. In cattle, dominance is probably determined within 24 hours of regrouping, and it may be related to age, sex, weight, presence of horns, and breed of the individual animals.

Cattle can display aggressive behaviors as the new dominance hierarchies are formed. Regrouping among younger animals produces less aggression and fighting than regrouping among older animals. This is particularly true with bulls. Dominance displays become more pronounced when the cattle have more limited access to resting areas, feed, and water. Dominance order is not permanent and may change depending on the age, health, or production status of the herd members.

Two types of cattle tend to be more aggressive than other herd mates. Bulls are usually larger and are unpredictable in their behavior toward humans and other animals. Cows that are protecting their young also tend to be aggressive, so handlers should exercise caution when handling or managing cows with calves. Cattle also behave aggressively or defensively toward any predator of the herd, such as a pack of dogs, a coyote, or a mountain lion.

Defensive behaviors for cattle are mainly "fight-or-flight" reactions. Usually if an animal has an escape route, it will simply avoid the intruder or stressor. If an animal is not restrained or isolated, it will flee back to the safety of the herd. However, if the animal is unable to flee, it may display defensive behaviors such as kicking, head butting, pawing, and even crushing. Personnel, whether on foot or on horseback, should take extra precautions when cattle are in a defensive position (lowered head position, shaking of the head, and pawing the ground with front hooves). 
Dogs. Dogs should be kept away from livestock unless they are properly trained and supervised. Domestic dogs have not been trained for work around livestock may chase and bite at cattle, causing the cattle to run uncontrollably. This fleeing action can have undesirable consequences for both the dog and the cattle. The dog may be kicked or butted by the cattle, causing injury to the dog. The cattle may be chased through fences or other hazards. In addition, the effort of long-term running can cause heat stress in the cattle or even initiate abortion in pregnant cows. Cattle that experience multiple attacks or chasing by domestic dogs may become more aggressive when any domestic dog or its owner enters the near vicinity, even if that dog is well-behaved and quiet. This aggressive behavior may be displayed especially around calving time. Depending on local regulations, a dog owner may be held responsible for monetary damages caused by cattle that are incited by his or her dog's behavior. Livestock owners may also have the right to kill any dog found in the act of killing or wounding livestock or, with conclusive evidence, any dog that the livestock owner can show has recently been engaged in killing or wounding livestock (California Food and Agricultural Code 31103).

Vocalization. Since cattle are relatively quiet animals, any vocalization is noticeable to caretakers. Vocalization is often associated with specific aversive events that may cause pain, frustration, or stress. A calf separated from its mother may vocalize in repeated calls. Bulls sometimes produce a low bellow prior to initiating an aggressive behavior. Cattle that are hungry may vocalize together as a group. Cattle may become aggressive, however, without any prior vocalization.

Daily behavior pattern. Cattle exhibit daily behavior cycles, especially for resting, grazing, and ruminating. These daily patterns may be dependent on the daylight-darkness cycle, dietary components, age of the animal, environment, temperature, and other stimuli. Cattle spend a variable amount of time eating, depending on their diet and the availability of feed. Cattle grazing on pasture or rangelands generally spend more time eating than cattle that are fed a concentrated feed. Most eating occurs during two periods of the day, just after dawn and just before dusk. Cattle tend to explore changes in their immediate environment and also will closely investigate novel objects. There may be an internal motivation for exploration that depends on the animal's age, weight, and sex. This kind of exploration involves using their senses along with locomotion skills.

Cattle have about 20 episodes each day of a drowsy or sleep state that may total 7 to 8 hours of rest. Grooming is performed by individuals and within groups. Often two animals will engage in grooming one another. Cattle stand close to each other and switch their tails to shoo flies away. They will also alter their lying position to protect sensitive skin areas from flies.

\section{STRESS}

A major concern to everyone involved in animal production relates to practices or conditions that may result in stress or pain to the animal. An animal is stressed if it is required to make abnormal or extreme adjustments in its physiology or behavior to cope with adverse conditions in its environment or management. By identifying and minimizing stressful situations in livestock production, producers encourage greater reproductive efficiency, growth, and well-being of cattle as well as economic benefits for the producers.

Fear in cattle is stressful and may cause both behavioral responses (such as balking and running) and physiological responses (such as an increased heart rate and hormonal changes). Cattle attempt to move away from fearful situations. A fear stimulus can be generated from any of a variety of sources, but most fearful responses have to do with 
experiences that are novel, occur suddenly, or are of high intensity. A sudden movement by a handler, an unexpected noise from a slamming gate, or an unfamiliar shadow: any of these may evoke fear in cattle. Noise as a fear stimulus often goes unnoticed by handlers in a cattle environment, but it can be frightening since cattle can hear higherfrequency sounds than humans hear. Also, a cow's long-term memory may play a role in associating fear with a particular event, such as unpleasant or abusive handling.

Stress from environmental and management aspects of beef cattle production can be classified into four broad categories: thermal (heat) stress, physical stress, disease stress, and behavioral stress. These are detailed below. The stress described in one category may also manifest itself by creating additional stress in another category.

Heat stress. Beef and dairy cattle are often exposed to high environmental temperatures in the summer months in California's Central and Imperial Valleys. When heat gain is greater than the animal's capacity for heat loss, cattle store the excess heat in the form of an increase in core body temperature. Animals dissipate heat using various heat-exchange processes, including evaporation, conduction, convection, and radiation. Cattle's response to heat stress involves changes in behavior, physiology, and performance. The negative effects of heat stress can be mitigated by making environmental modifications to the corrals of confined cattle in order to manage thermal load, animal behavior, and the thermal impact.

Heat flow is a function of the temperature gradient between the animal and any surface it comes in contact with, as well as the thermal conductivity of the surface. If the surface is cooler than the animal, the animal will transfer heat to the surface, reducing the animal's heat load. This is an important consideration in the environmental design of animal facilities. In general, shade or moisture will decrease ground surface temperatures, facilitating opportunities for increased heat loss in hot climates. An animal lying on a shaded or wet surface has a higher conductive heat loss. In contrast, when the ground surface temperature is higher than the animal's skin temperature, the animal that lies on the ground gains heat by conduction. A standing animal's conductive heat exchange is minimal because the animal's body exposure to the ground surface is minimal.

Radiant heat gain is an animal's absorption of heat in the form of infrared electromagnetic waves given off by the sun. Cattle with dark colored coats have a higher internal temperature than cattle with light colored coats when both are exposed to the same solar radiation because darker colors absorb more infrared solar radiation. The provision of shade to reduce radiant heat gain is considered one of the most effective ways to mitigate heat stress in cattle.

Behavioral, physiological, and performance responses to heat stress. The first way that cattle respond to heat stress is through behavioral modification. In hot conditions, cattle seek cool (i.e., shaded or wet) locations and exhibit changes in feeding, drinking, standing, lying, locomotive, aggressive, and elimination behaviors, as well as in their utilization of the corral space. Like most mammals, domestic cattle are most active during the day and rest at night. Cattle that are kept on pasture exhibit a nocturnal grazing pattern, grazing predominantly at dusk and dawn with minimal grazing in the afternoon hours and at night. Cattle grazing patterns are greatly influenced by heat. In the summer or in tropical climates where temperatures and humidity are high during the day, cattle do most of their grazing at night. During the day, they spend most of their time seeking cover, idling, or resting.

Another response to heat stress is an increase in consumption of water, which provides the means for heat loss via respiration and sweating. A high heat load leads to an increased rectal temperature and increased respiration rate, the latter of which permits more evaporative heat loss via the upper respiratory passages. An animal's failure to regain its normal body temperature overnight is a critical factor that will limit 
its productive ability and further heat dissipation mechanisms. If the cow cannot dissipate excess heat (e.g., during the night), that heat load will continue to increase, leading to physical distress or even death.

If behavioral thermoregulation and increased water intake cannot sufficiently reduce their body heat, cattle will lower their metabolic heat production by decreasing their dry matter intake (DMI) associated with feed. A reduction in DMI reduces the cow's internal body temperature. Feed quality can have a greater impact on a cow's heat load than solar radiation due to the amount of metabolic heat produced during digestion. An ambient temperature above $102^{\circ} \mathrm{F}\left(39^{\circ} \mathrm{C}\right)$ will prompt most cattle to reduce their DMI, which consequently lowers their average daily gain and feed efficiency. However, cattle that are acclimated to desert environments may maintain their DMI when daytime temperatures rise above $105^{\circ} \mathrm{F}\left(41^{\circ} \mathrm{C}\right)$, though they will decrease it if nocturnal lows stay above $80^{\circ} \mathrm{F}\left(27^{\circ} \mathrm{C}\right)$.

Physical stress. The physical component of an animal's environment includes the space available to it and the surfaces with which the animal comes into contact. Physical stress may include environmental factors such as the availability of space in a housing facility, the lack of proper maintenance for safe housing or confinement facilities, flooring design, or restraining procedures. Injuries also fall under the category of physical stress.

Disease stress. Stress that results from the onset and spread of disease constitutes disease stress. The ability of an animal's immune system to respond to an infection will determine whether the animal will succumb to or survive a clinical disease. "Shipping fever" (Bovine Respiratory Disease Complex) in cattle is often associated with transport.

Behavioral stress. A number of stress mechanisms affect the normal behavior of cattle, and these are grouped as behavioral stress. Fear and anxiety are forms of behavioral stress. To minimize behavioral stress, adequate areas should be provided for activities such as feeding, sleeping or lying, and grooming for all herd mates. When selecting the type of restraint or handling method to be used for various management practices, consider options that minimize the level of fear and anxiety in the cattle.

There is no practical, reliable method for evaluating behavioral stress besides observation. Short-term stress can increase an animal's heart rate, respiration, some hormones, and blood pressure. Long-term stress may induce changes in immunological response or hormonal secretions. This kind of stress may be quantified by studying behavioral adaptations to a specific stressor. Research suggests that some objective methods may yet be developed to measure behavioral stress, but to date these have not been validated under field conditions.

While difficult to quantify, there are observable indicators of behavioral stress. Cattle experiencing behavioral stress often exhibit one or more of the following signs:

- Lack of appetite

- Abnormal posture

- Restlessness

- Elevated respiratory rate

- Lameness or alteration of gait

- Dull or depressed attitude

- Grunting or other unusual vocalizations

- Lack of grooming

- Self isolation from the herd or pen mates. 
Pain. Pain and stress are distinct from one another. An animal's perception of pain is initiated by stimuli that transmit information to the central nervous system via receptors located in the skin, muscles, viscera, or joints. The animal then responds through physiological and behavioral changes similar to those exhibited during stressful situations. However, pain symptoms are often more acute or have a more sudden onset.

Some of the practices used in beef production (e.g., vaccination, branding, dehorning, castration) can be short-term stressors and may also be painful. Other management practices such as gathering cattle to move to new pastures, separating calves from their dams during processing or weaning, and sorting may also cause short-term stress. Some tools, such as the restraints used when performing certain production practices, create short-term stress but provide a safer environment for both the cattle and livestock personnel. Although some management practices cause stress over a short period of time, these practices have large net benefits to the health and wellbeing of the animals. These practices aid individual animals and their herd mates or pen mates by alleviating some kind of long-term stress or the risk of stress from injury, disease, or nutritional factors. Beef producers must consider how to manage stress through practices that may be short-term stressors, but will improve the long-term well-being of their animals.

\section{IDENTIFICATION}

A system for positive identification of individual beef animals is necessary for several reasons. As proof of ownership, most beef producers brand their cattle with a hot iron. The California Bureau of Livestock Identification regulates the use of brands and employs inspectors who monitor the sale of cattle to verify proper ownership. The act of cattle rustling is of understandable concern to animal producers. Stolen animals may suffer mistreatment while they are being transported and hidden. Cattle rustling still occurs in California, and unidentified animals are at a much greater risk of theft than identified animals.

Identification also is necessary for many management reasons. The recordkeeping required for effective genetic improvement and selection in a herd depends in large part on the accurate identification of sires and dams and their sons and daughters. Herd health records for vaccination, medications, and parasite control also depend on the proper identification of individual animals. Diseased or injured animals need to be easily and accurately identified and, if necessary, removed from the herd for treatment. Proper identification can help producers prevent the inappropriate breeding of individuals that could yield genetically deformed or unfit offspring. Confined or feedlot cattle are identified to provide management personnel with proper health and feeding information. Identification also protects consumers by ensuring that producers can follow the appropriate withdrawal times prior to slaughter when an animal's health dictates the use of antibiotics or other medications or that they can identify and segregate treated or unhealthy cattle from the human food supply.

Methods used to identify cattle in the past have included hot iron branding, ear marking, tattooing, ear taggings, wattles, and freeze branding. Hot iron branding is the only currently legal method for proof of ownership. All brands must be registered with the California Bureau of Livestock Identification (www.cdfa.ca.gov/ahfss/li/). To produce a legible brand, a heated branding iron is applied to the skin for several seconds while the animal is restrained. The length of time the branding iron is in contact with the skin depends on the time of year, the breed of cattle, and the length of the hair on the animal. Only experienced or trained personnel should brand cattle.

Earmarks augment hot iron brands, especially when brands are not easily visible. Earmarks may be registered with the brand. Earmarks are made with a clean, sharp knife, cutting a portion of the ear with a specific notch, slit, fork, or other-shaped 
mark. This can be done at branding time. It may produce short-term stress and pain for the cattle, but may also decrease the stress of excessive handling required for positive identification later on if other identification marks become illegible.

Tattooing on the inside of the cow's ear is a permanent form of identification that is used in the brucellosis vaccination program in California and also is commonly used to identify individual animals in a purebred herd. Tattooing requires specialized equipment and restraint of the animal. Brucellosis vaccination can only be applied by a USDA-accredited veterinarian.

Ear tags of many different styles and types are commonly used for identification. Ear tags are useful for management purposes, but are not considered permanent identification because they can be removed or lost. A tag is commonly supported by a plastic or metal shaft that pierces the ear and is held in place by a fastener on the back of the ear. The tags are relatively easy and quick to apply and require less restraint of the animal than other forms of identification. Tags should be applied in an area of the ear that is free of large blood vessels to reduce bleeding.

Freeze branding is another form of permanent marking, but it is used less often than other identification methods. Freeze branding requires more expertise on the part of the handler and more restraint of the animal than hot iron branding. The hair around the branding site must be clipped and a liquid, cold-transfer agent must be applied to the site to be branded. Freeze-branding irons are chilled in a dry ice and alcohol solution or in liquid nitrogen and then are applied to the skin of the animal to produce the brand. The freeze-branding iron has to remain in contact with the skin longer than the hot iron. Freeze branding destroys the natural pigmentation in affected hair so that, over the course of a few weeks, the growth of white hair in the area forms a legible brand. Because this method results in the growth of white hair, animals with light-colored hair do not show freeze brands well. Adequate freeze brands on cattle with dark hair are readily visible from some distance.

Wattles are used as an alternative ownership identification tool in colder climates where longer winter hair growth makes brand recognition difficult. This form of identification consists of surgically separating both layers of skin from the connective tissue resulting in fingerlike formations about 2 to 4 inches long. Wattles are commonly located on the cattle's dewlap, neck, or shoulder. Animals experience short-term stress when the wattle procedure is performed, but proper wattles may prevent repeated handling of the animal to identify its owner. This identification method is used mainly in the cold intermountain region of California and is not a necessary or generally utilized form of cattle identification in other regions.

Hot iron face branding may be required by the USDA to identify animals for specific, highly important identification purposes. These include identifying animals that carry certain contagious diseases, animals selected for herd reduction programs, or feeder cattle imported from Mexico. This method is not suitable for proof-of-ownership or individual identification purposes and is not used by producers.

The National Animal Identification System (NAIS) is a new cooperative State-FederalIndustry program administered by USDA's Animal and Plant Inspection Service for the purpose of tracking animals' movements between locations from birth to slaughter. The long-term goal of the NAIS is to trace back within 48 hours all of the locations (premises) where a suspected diseased animal has been during its life and to provide information on all of the other animals that may have come in contact with the subject animal at each location. The program's goal is to improve animal health. The NAIS is currently a voluntary program, so producers and other stakeholders can participate in design, development and testing of the system to ensure that practical solutions are developed. Premises identification is the responsibility of the livestock owner and can be obtained through the California Department of Food and Agriculture. 


\section{NUTRITION}

Cattle's ability to readily consume and absorb nutrients from many different feedstuffs is attributable to their ruminant digestive tract. Ruminants are characterized by their fourcompartment stomach and cud-chewing (rumination) behavior. In one of the compartments, the rumen, feed undergoes microbial fermentation, which makes absorbable nutrients available to the animal. Often, ruminants consume feedstuffs that are unsuitable for many other types of animals. The Food and Agricultural Organization of the United Nations estimates that more than 65 percent of the world's land mass cannot be farmed and can only be harvested by ruminant animals.

Feed of an adequate quantity and quality are required for cattle's body maintenance, pregnancy, and growth. Which feeds and feeding practices a producer selects will depend on availability, costs, and environmental conditions, and the nutrient requirements of the cattle. Factors that affect cattle's nutrient requirements include their breed, sex, age, weight, and genetics, as well as their production stage (such as growth, lactation, or pregnancy).

Numerous attempts have been made to establish objective, numerical standards for normal compounds or chemicals in the body (metabolic profiles) that could be used to evaluate an animal's nutritional status. Many constituents found in the circulatory system have been measured and data published indicating averages and ranges. However, metabolic profiles do not constitute a practical, useful tool. For example, different feeding regimes will influence protein levels in blood (serum), but the changes are subtle and difficult to detect or interpret.

Numerous dietary components or elements are essential in the diet of beef cattle. These include water, energy, nitrogen, minerals, and fiber. The National Research Council publishes bulletins and periodic updates that are generally accepted as good nutritional guidelines and reliable references.

Minerals. Minerals required in cattle rations include calcium, phosphorus, cobalt, copper, iodine, iron, magnesium, manganese, molybdenum, potassium, selenium, sodium, zinc, and chlorine. Other elements (e.g., chromium) have been suggested as essential, but little scientific data is currently available that is applicable to cattle. Interactions between minerals further complicate requirement levels in cattle diets. In addition, there are minerals that should not be fed above certain levels. Federal and state regulations apply to some of these minerals. Forage-grazed cattle that have a deficiency in the required minerals may require minerals supplements.

Vitamins. The vitamins cattle require may be supplied in feedstuffs or synthesized by body tissues or by microorganisms in the rumen. Vitamins B and $\mathrm{K}$ are produced in the rumen soon after solid feed is introduced in the diet. Vitamin D is synthesized when the animals are exposed to sunlight and is also found in sun-cured forages. High-quality forages also contain large amounts of vitamin A precursors and vitamin E. Vitamins A and E are the only vitamins likely to be of practical importance in terms of supplementing the diets of cattle.

By-product feeds. California's vast and varied agricultural production system produces large quantities of agricultural by-products. These by-products are generally unwanted, but their disposal can pose problems and may contribute to higher prices for their primary products. Many of these by-products, however, can provide nutrients required by beef cattle. Beef cattle are capable of utilizing a number of by-products produced in the processing of other agricultural products for human consumption. Examples include brewers' grains, beet pulp from sugar production, citrus pulp after juice extraction, cottonseed after the cotton fiber is removed, and milling commodities from the production of flour. Various regulations are in place to ensure safety when agricultural by-products are used as feed for cattle. 
Feed additives. The U.S. livestock industry has been using feed additives for more than 30 years. Some of these additives help reduce digestive disturbances that may result from feeding high-energy feeds to cattle. Antibiotics may be fed as additives to provide therapeutic protection from disease. The Food and Drug Administration (FDA) regulates both the type and amount of antibiotics that can be fed to cattle. Research indicates that when antibiotics are used in compliance with FDA standards, no residues can be found in beef products. The antibiotics used as feed additives in cattle production are not therapeutic agents for humans, so the potential for development of antibiotic resistance in human pathogens is not an issue.

Ionophores make up another class of feed additives used primarily in feedlots. Since ionophores are not absorbed by the animal but act within the rumen to enhance digestion, no residues from these products are found in the carcass. When fed, ionophores are added in very minute amounts (only grams per ton of feed) to increase feed digestion efficiency and decrease methane emissions into the environment. As with all feed additives, the use of ionophores in cattle feed is regulated by the FDA.

Calf nutrition. Occasionally a calf may need feed supplementation because it has been orphaned or is not receiving enough milk from its dam. This supplementation will differ from what an adult animal would receive because the calf's rumen is much less developed. A young calf poorly utilizes roughages and other dry feeds that are commonly fed to mature cattle. Thus, commercially available liquid milk replacers can be fed to a calf to meet its nutrient requirements. If the calf is a newborn, special care should be taken to assure it has received colostrum during the first hours after birth.

Prohibited feedstuffs. Since August, 1997, the FDA has prohibited the use of protein derived from mammalian tissues (with certain exceptions including milk, blood, porcine, and equine products) in ruminant feed. A ruminant is defined as any animal that has a four-chambered stomach, including cattle, buffalo, sheep, goats, deer, elk, antelope, and several other species. Feed manufacturers are required to label any feed that contains prohibited materials with the statement, "Do not feed to cattle or other ruminants."

Feeding practices for grazing cattle. Grazing cattle consume a varied diet that may include grasses, legumes, forbs, and brush (browse). In many cases, range situations appear to provide insufficient feed or variable feed quality for cattle. The height of forage by itself is not a good indicator of forage quality or the nutritional status of grazing cattle. The nutritional quality of forage for grazing animals decreases as the plants mature. However, as the quantity of the forage increases, the total nutrients available to the animal from a given acreage of range may increase. Recognition of the possible varied diets of the grazing animal and consideration of the evaluation methods previously discussed will guide the trained observer in assessing the nutritional adequacy of range feeding for beef cattle.

Water of suitable quantity and quality should always be available to cattle. During hot or extremely cold weather, check the water supply daily. During freezing temperatures, make adequate water available at least once (and preferably twice) daily.

Producers should strive to reduce periods of inadequate nutrition for grazing cattle, either by supplementing the forage with other feedstuffs or by moving the cattle to another location where more feed is available. Cattle can, however, cope with temporary periods of low levels of nutrition. Without human intervention, beef cattle and wild ruminant animals commonly undergo periods of poor nutrition and decreased body condition. Younger cattle are more susceptible than older cattle to the effects of inadequate feed. During periods when feed may not be available in adequate quality or quantity, the producer's efforts to provide supplementary nutrition should focus on the needs of younger cattle. Such periods can occur during drought, extreme snowfall, or flooding, or in other situations beyond human control. 
Body condition and the ability to mobilize reserves for periods of inadequate nutrition should be assessed. Body condition affects certain body functions. The ability to sustain such functions as growth and reproduction can be related to the animal's well-being. Cattle body condition scores will have normal variations during the year due to variations in feed availability and the animal's reproductive status. Attainment of specific body reserves or condition could be used as a guideline to animal nutritional well-being and potential for life cycle activities. Scoring systems have been developed to estimate body condition (Mathis, Sawyer, and Parker, 2002; also see Appendix 1 of this publication).

Cattle producers use supplemental feeds to increase nutrition when nutrient deficiencies exist in range forage. A variety of supplemental feeding methods are available using various products and management strategies. At times, feeding a minimal amount of concentrated protein, energy, or mineral supplements may correct nutrient deficiencies in the forage. In other situations, hay is fed to supplement the grazing animal. Contamination of supplemental feeds with mold, manure, spoiled feed, mud, or dust may compromise the health of the animal.

Land managers using cattle for vegetation management are often concerned about the use of supplemental feeds. They note that supplemental forage can introduce weeds and that supplemental feeding locations can become areas of overutilization. When used appropriately, supplemental feed is an important grazing management and nutrition management tool. Moving salt or mineral feeding locations away from water is one way to alter livestock distribution. In the past, producers believed that livestock must have water immediately after consuming salt. Recent information indicates that this may not be necessary. Periodically changing the feeding location is also an effective tool for encouraging livestock distribution. For example, hay piles can be placed far apart with more piles than the number of cattle being fed. This can improve distribution and may reduce trampling.

The appropriate supplement can also be important in improving forage utilization on the range or pasture. In particular, the annual range plants during California's dry summer and fall can be very low in crude protein. A supplement protein source in the form of high-protein forage like alfalfa or a liquid such as molasses or urea formulations may provide cattle with enough nitrogen (and thus protein) to complement the low-quality forage of the range or pasture. Always exercise caution when using urea as feed, since high levels or periodic feeding can cause urea toxicity.

Feeding practices for confined cattle. In California, calves or stocker cattle typically remain on rangelands or pastures until they weigh 600 to 800 pounds. Cattle then enter feedlots as "feeders" for 90 to 150 days to reach a market weight of 1,150 to 1,250 pounds or more. Feedlots in the desert regions of California receive cattle weighing 275 pounds or more. These animals are fed for 240 to 270 days and reach a market weight of 1,050 to 1,300 pounds.

Calves are often transported long distances to the feedlot and may arrive at the feedlot in a stressed condition. The care and treatment that calves receive upon arrival at a feedlot facility depends on whether they have been preconditioned. Preconditioning is the practice of castrating, de-horning, and implementing vaccination and deworming programs prior to the animal's arrival at the feedlot. Preconditioning adds value to calves since its purpose is to reduce sickness, lower death loss, reduce weight loss, and increase the feed efficiency of the calves at the feedlot. If the feedlot manager has some guarantee that calves have been preconditioned, much of the initial stress on arrival at the feedlot may be avoided. Preconditioning is particularly helpful when calves are being shipped from stocker operations. These calves should be castrated and dehorned at the stocker operation rather than at the feedlot since the stress of castration and dehorning increases with the age and weight of the calves. 
Most calves that arrive at feedlots have prior experience eating hay. Unchopped, long grass hay should be offered to the calves in feed bunks upon their arrival. Water may be offered to calves soon after arrival, but most calves will not have experience drinking from water troughs, drinkers, or other containers used for water supply in the feedlot. Since calves usually recognize the sound of flowing water, water should be allowed to flow continuously into these water containers for 12 to 48 hours after the calves' arrival. Continue to feed long hay to the calves for the first 48 hours after arrival, and then offer the calves chopped hay with increasing amounts of the finishing feedlot ration. This transition in feeding will usually take 4 to 6 weeks, at the end of which time the calves will be fed only on the "finishing ration."

If the feedlot manager has no guarantee that calves have been preconditioned, he or she must assume that the calves must be "processed" when they arrive at the feedlot. In this case, processing is the practice of castration, de-horning, and implementation of vaccination and deworming programs. Processing should take place as soon as is feasible, since delay will only extend the initial, stressful arrival procedure. Calves usually take 5 to 7 days to recuperate from processing and should be monitored carefully during this period. During this recuperation period it is important that calves drink water and eat hay. Calves that develop nasal discharges or isolate themselves from pen mates may be sick. A veterinarian will provide recommendations for the treatment, management, and care of sick cattle. This may include moving sick calves to a hospital or "sick" pen for medical treatment and observation.

Cattle in California's feedlots are fed high-energy diets of feed grains and byproducts. High-energy feeds increase the cattle's daily weight gains and feed efficiency, reducing the number of days they will take to reach market weight and maximizing the feedlot's output of a high-quality product. Unlike range or pasture operations, where quality and quantity of forage change over time, the nutrient intake of animals in feedlots is controlled and more consistent.

Feedlot managers should participate in quality assurance programs to ensure that the feeds used in their rations are of adequate quality. The feed supplies also have a quality assurance program to satisfy the needs of the feedlot for residue-free feedstuffs that meet FDA, Environmental Protection Agency (EPA), and state regulations regarding pesticide tolerances in animal feeds. The program includes a method for recording the quality of feed being used by the feedlot and for maintaining records of all feed additives used by the feedlot. These records must be kept for at least 3 months after the cattle are slaughtered.

\section{ANIMAL HEATH PRACTICES}

Herd health preventive program. The details of a herd health program that addresses the prevention and treatment of disease vary depending on what type of beef cattle operation it is designed to serve. There will be differences between programs for grazing and confinement facilities, cow-calf and stocker operations, and operations run in different regions of the state (because of local environmental factors). While there can be many differences in detail, the health program should always be part of the total cattle management program, incorporated into facility design and all feeding, reproduction, handling, and transportation practices. Every producer should have a licensed veterinarian help design and implement a herd health program. The veterinarian can also provide help with information about and selection of products and management options.

Diseases common to cattle and humans. A number of diseases that affect humans also affect animals, and these are referred to as zoonotic diseases. In fact, of all the infectious diseases known to exist, more than half affect both humans and animals. Diseases that affect both cattle and humans include brucellosis, tuberculosis, rabies, and bovine spongiform encephalopathy (BSE). There are active programs currently in place to 
eliminate these diseases from cattle and prevent their spread to humans. All cows that are retained for breeding purposes are vaccinated against brucellosis with the RB-51 vaccine. Additionally, adult dairy cows going to slaughter are tested for brucellosis. The milk from all dairies is tested two times a year for brucellosis. Brucellosis has been virtually eliminated from domestic cattle in the United States and Canada. All slaughtered adult cattle become part of the tuberculosis surveillance system and all are examined for possible lung lesions due to tuberculosis. Most states in the United States are certified tuberculosis-free and the chance of spread from cattle to humans is remote. In contrast, tuberculosis cases in humans (person-to-person spread) are increasing. With regard to BSE, many surveillance and preventive measures have been adopted by government. The preventive steps include a ban on feeding by-products derived from ruminant animals back to ruminants such as cattle and sheep (ruminant-to-ruminant feed ban), the removal of specified risk materials from each carcass, and an aggressive surveillance program for at-risk cattle. Because of society's long relationship with cattle production, it is important to continue the prevention and elimination of these diseases between humans and cattle.

Disease prevention can require management changes. A number of cattle diseases can dramatically alter the management system. In California several of these conditions are common, including epizootic bovine abortion (EBA; foothill abortion), anaplasmosis, Trichomonosis, and pinkeye. Both EBA and anaplasmosis are tick-transmitted diseases and their prevention requires significant management changes since the complete elimination of ticks is not possible. In the case of EBA, cows and heifers should only be placed in fields where exposure to the ticks is possible when they are either not pregnant or are more than 7 months pregnant so that exposure will not occur when the fetus is susceptible to the agent. For anaplasmosis prevention, certain vaccines must be given to cattle over 2 years of age, while a different type of vaccine is appropriate for cattle less than 11 months of age. Pinkeye prevention often requires the use of insecticide ear tags and close monitoring of the cattle during the summer months. Trichomonosis is a venereal disease of cattle and bulls and may seriously impact the number of calves produced in the herd. Trichomonosis control is mainly achieved by testing all bulls prior to the breeding season. In herds with a history of Trichomonosis, cows and heifers can be vaccinated. The vaccine is not effective in bulls. These procedures require added labor, expense, and risk when handling animals, especially the bulls.

Medical therapy and parasite control. The use of products that control parasites and treat sick animals is essential for the humane treatment of cattle, disease control, and optimized beef production. All drugs used for cattle must be approved by the FDA, EPA, USDA, and in some cases the California Department of Food and Agriculture (CDFA). These must be shown to be safe and effective for cattle and, in addition, safe for consumers and the environment. Each product must be developed to include science-based methods for storage, dosage, route of administration, withdrawal times, and precautions. Approved drugs must list the dosage, route of administration, species of animal, diseases or conditions for which it is approved, withdrawal time, and precautions on its label. The label is a legal document and any user is obligated to adhere to all of the conditions on the label. Any deviations from the label are referred to as extra-label drug use and can only be done under direction of a licensed veterinarian. The veterinarian must write a prescription for any extra-label drug use that is specific to the condition and individual operation. The veterinarian is then responsible for any adverse reactions that might occur. Extra-label drug use cannot be used for production enhancement, disease prophylaxis, behavior, or reproductive management. Extra-label drugs cannot be mixed into feed. 
There is an extensive list of drugs that cannot be used in food animals under any conditions. Additionally, records of herd vaccinations, parasite control treatments, and individual treatments should be maintained. In particular, records of antibiotic treatments in individual animals must include the withdrawal time, which is the time period that must elapse between the last antibiotic treatment and the animal's slaughter to avoid the possibility that residues will remain in the meat products. More specific and up-to-date information on medical therapies appropriate for beef cattle can be obtained through participation in the California Cow-Calf Quality Assurance Program (California Cattlemen's Association, 1994).

Care of sick or injured cattle. To reduce stress from disease, experienced personnel should regularly check groups of cattle for the presence of sick animals. Cattle in confinement should be checked at least daily and cattle in pastures or on rangeland should be observed as often as is feasible. A combination of factors involving the cattle's susceptibility, environmental conditions, and the presence of a disease agent is necessary for disease to occur. Producers need to manage their animals to reduce or prevent the incidence of disease. If disease or injury does occur, prompt treatment options should be considered, possibly with advice from a veterinarian.

In confinement operations and, when feasible, in grazing operations, sick or injured cattle should be held in separate "sick" or "hospital" pens while they receive treatment. This isolates them from healthy animals and reduces the transmission of disease. It can also reduce stress in the sick animal. Each affected animal should be positively identified before treatment. If the treatment involves antibiotics, the type and amount used should be noted for each animal. These records and those described below are integral parts of a quality assurance program to ensure the wholesomeness of beef products. Cattle treated for disease with antibiotics cannot be marketed in specialized markets such as a natural beef program.

When an animal is injured, suffers from a degenerative disease, or is of advanced age and is declining in condition or mobility, additional care may be needed. This may include veterinary care, supplemental feed and water, and protection from other cattle and adverse environmental conditions.

When an animal responds to treatment and recovers but cannot return to the breeding herd or the feedlot, it should be culled and sold for slaughter. The animal can only be slaughtered after the required withdrawal time for any medication has passed. If the animal does not recover and becomes physically impaired or non-ambulatory, it should be humanely euthanized. It is illegal to transport or sell animals in this condition.

Mortality and morbidity. As with other living organisms, morbidity and mortality occurs in cattle. Despite all the efforts a producer might make to provide health care to cattle, a small percentage of the herd will die at birth or later from disease, injury, or other causes. During the production year in California, the mortality for beef cattle operations ranges from 1 to 3 percent.

When an animal dies from unknown causes, the decision of whether to perform a necropsy (autopsy) should be made with the advice of a veterinarian. A necropsy may provide information that can be used to adjust health program for the rest of the herd.

The carcass of a dead animal may present a health risk to other cattle in the herd or pen and emit odor, so it should be disposed of promptly to reduce the spread of disease and minimize the odor. The method of disposal (i.e., burial, burning, or if feasible, rendering at a licensed rendering facility) may depend on the cause of death. State law and local ordinances may define the manner in which a producer is allowed to dispose of dead animals. In California, growers can consult CDFA for information on animal haulers, rendering facilities, and collection centers (online at www.cdfa. ca.gov/ahfss/ah/haulers_renders_collection_centers.htm). 
Euthanasia. Occasionally it becomes necessary to euthanize cattle due to any of a variety of causes, such as severe trauma or injury, disease, inability to stand or walk, or severe calving complications. The objective of euthanasia is to provide the animal with a swift and humane death, thus quickly alleviating its pain and suffering. An action plan should be developed with the assistance of a veterinarian for use with cattle in these emergency situations. Different protocols may be recommended for cattle of various ages at a facility. Personnel who routinely handle or transport cattle should be trained to perform the euthanasia procedures. Correctly performed, euthanasia will minimize the pain and discomfort the animal experiences and ensure the safety of personnel.

Several common methods of euthanasia are utilized for cattle. Chemical euthanasia using an injectable barbiturate solution is performed by veterinarians, whereas physical methods such as a penetrating captive bolt or gunshot can be performed by trained personnel.

Chemical method. The intravenous injection of barbiturate chemical derivatives will depress the cow's central nervous system and lead to unconsciousness followed by respiratory and cardiac arrest. This method has limitations, since only licensed veterinarians have access to barbiturate products. Also, animals must be handled and restrained while the injection is administered. Carcasses that are euthanized by barbiturate chemicals should be protected prior to disposal to prevent scavenging by other animals and they should not be used for human consumption or fed to other animals such as cats, dogs, or wildlife scavengers, since residues of the euthanasia solution may remain in the carcass. Some local rendering services may not accept carcasses that contain euthanasia solution.

Physical methods. Penetrating captive bolt and gunshot are two euthanasia methods available to non-veterinarians. These methods physically disrupt brain activity. A penetrating captive bolt stunner is the preferred method because it does not fire a free bullet and so is less likely to cause unintended, accidental damage. A captive bolt stunner can be purchased from a packing plant supply company. The stunner fires a blank cartridge that propels a steel bolt into the animal's brain, producing immediate brain tissue destruction and stunning of the animal. The point of entry for cattle should be in the center of the forehead, at the intersection of two lines drawn from the inside corner of the eye to the base of the opposite horn-not between the eyes. Euthanized animals should be exsanguinated (bled out) after use of a penetrating captive bolt stunner or gunshot to insure death. To exsanguinate the animal, sever the large blood vessels, such as the carotid artery or the jugular vein..

The advantage of gunshot is that it does not require close human contact with the animal. A .22 caliber hollow- or soft-point bullet is sufficient for a young animal, but larger mature animals will require at least a .22 magnum solid-point bullet or, preferably, a $9 \mathrm{~mm}$ or .357 caliber bullet. The point of entry in cattle is the same as for the penetrating captive bolt. The firearm should be held perpendicular to the skull and within 2 to 10 inches from the point of intended impact. Do not place the firearm directly against the animal's head. There is always the potential for ricochet when using firearms, and laws or regulations may prohibit the discharge of firearms in certain locations.

Monitoring vital signs. It is essential to confirm that the animal is dead by examining it for vital signs. Death is confirmed by lack of breathing, heartbeat, and corneal (eye) reflex. Additional euthanasia procedures should be initiated if there is evidence of responsive vital signs. For more specific information on euthanasia methods in cattle, refer to the website of the American Association for Bovine Practitioners (www.aabp.org/resources/euth.pdf). 


\section{COMMON MANAGEMENT PRACTICES}

Many practices used in beef production require the services of experienced or trained personnel. Some procedures require a veterinarian. When processing cattle, only qualified personnel with knowledge of the procedure to be performed should be used to minimize the animals' stress, discomfort, and pain. Procedures such as vaccination, castration, dehorning, and artificial insemination are normally performed by producers and their employees. Licensed veterinarians should perform any invasive surgery and administer restricted vaccines.

Castration of bulls. Sexually mature male cattle are more aggressive than castrated males (steers) and so are more likely to injure themselves, other cattle, or handling personnel. In grazing operations, intact males present managerial problems that may include fighting, riding other cattle, and unwanted pregnancies within the herd. The standard for beef quality is also an important consideration. Carcasses from intact males, 9 to 30 months of age, are graded as bullocks. Bullock carcasses may be USDA quality graded, but they have a lower value than steer and heifer beef carcasses.

Regardless of the procedure selected, only experienced and trained personnel should castrate cattle. Castration of bull calves at the earliest possible age is preferred. Castration is least stressful if performed before 2 to 3 months of age. If a calf is heavier than 500 pounds, local or general anesthesia should be administered by a veterinarian or other trained person when surgically removing the testicles or using a non-surgical castration technique such as the Burdizzo method of crushing the spermatic cord (Burdizzo or elastrator; see next paragraph). Provisions should be made for control of bleeding and animals should be kept in a clean area until healing is complete. Postcastration care of calves should include special attention and management during the week after the procedure. Nursing calves should be returned to their dams in a clean area. Calves should be checked to ensure that they are nursing or eating, the bleeding has stopped, and the wound is healing normally.

Several methods are available for castrating bull calves. One non-surgical procedure uses an instrument called a Burdizzo. The Burdizzo method should be performed at least 24 hours after birth but before 2 months of age. This procedure requires that the male calf be restrained while the specially designed tool is placed on the scrotum above the testicles and is closed, crushing the spermatic cord. This action severs the blood supply, causing atrophy of the testicles. Proper use of the Burdizzo requires skill, and improper use may result in only partial castration. Post-castration discomfort or pain from the use of the Burdizzo is comparable to that resulting from other castration methods.

Another non-surgical castration procedure uses a tool known as an elastrator. Elastrator bands should be applied at least 24 hours after birth but before 7 days of age. Specially designed large, strong rubber bands are slipped over the testicles and released on the scrotum above (proximal to) the testicles, constricting the blood supply to the testicles. After several days, the testicles and scrotum degenerate and separate from the calf's body. Like the other non-surgical procedure, failure is possible, for instance if the rubber band breaks or is not properly applied. Post-castration discomfort is longer with this method than with others. Larger bands made of surgical tubing can be used in a similar manner on larger and older cattle. Tetanus is a risk factor when producers use castration bands, particularly on older cattle.

Removal of the testicles using sharp cutting instruments and emasculators involves opening the scrotum and severing the testicles from the spermatic cords. Follow aseptic techniques and use trained personnel to reduce the possibility of postcastration bleeding or infection. Only use clean, well-maintained cutting instruments and emasculators. The wound should be treated to prevent infection and fly control 
should be applied. Castration failure is less likely to occur with this surgical procedure than with the non-surgical procedures because the testicles are actually removed at the time of surgery. Post-castration discomfort using this method is normally shorter than when using an elastrator band.

Chemical castration has been used in the past, but there are no current products commercially available. Chemical procedures are bloodless but require extreme skill because the chemicals must be injected directly into the testicles. These procedures are slow and prone to error.

Spaying of heifers. When sexually mature heifers are not selected to enter breeding herds, they are normally managed to eventually enter a feedlot. Before entering the feedlot, though, they may become pregnant. A pregnant heifer may calve in the feedlot, depending on the stage of fetal development and the length of time it remains in the feedlot. This creates a stressful situation for the heifer and a high probability of mortality for the calf. To prevent this situation, producers can ovariectomize (spay) heifers that are not selected for breeding or they can induce pregnant heifers to abort soon after heifers enter the feedlot. Spaying is the surgical removal of the ovaries from the heifer. Performed by a trained veterinarian, it requires abdominal surgery. Spaying is not a common practice in California.

Planned abortion. Inducing abortion involves a single injection of an FDAapproved drug that affects the physiological function of the ovary during pregnancy. When the drug is administered during the period from early to midterm pregnancy, it can terminate the pregnancy with no observable stress or discomfort to the cow.

Dehorning. Calves are born with or without horns, depending on their genetic makeup. Cattle with horns are routinely dehorned to prevent injury to herd mates and handling personnel, increase ease of handling, and decrease the space requirement at the feeder. In confinement, cattle with long horns can injure themselves by getting their horns caught in fences, gates, and chutes. Dehorn cattle at an early age, usually between 2 and 10 weeks old. Calves older than 10 weeks are difficult to restrain and have an increased risk of blood loss, fly infestation, and possible infection. For calves older than 10 weeks, a veterinarian or trained personnel should administer a local anesthetic before dehorning. Horned cattle that arrive at feedlots should either be dehorned soon after arrival to avoid prolonged stress on the animals or simply not dehorned at all.

Regardless of when dehorning takes place, only experienced or trained personnel should perform this procedure. When a surgical procedure is required for the removal of horns, aseptic methods using well-maintained tools or instruments are necessary. Following removal of the horn, the resulting wound should be treated to prevent excessive bleeding, control flies, and prevent infection. If feasible, check dehorned cattle daily during the first week to ensure that their wounds are healing properly. Weight gain or growth may be depressed in older cattle following dehorning.

Cattle are dehorned by any of several methods or a combination of methods, depending on the age of the animal and the size of its horns. Application of a hot dehorning iron is the simplest and fastest way to destroy the cells producing the horn and prevent its further growth. Caustic dehorning liquid or paste can be applied to the horn "button" of calves during the first few weeks of life to stop the horn's growth, but it generally causes more prolonged pain and discomfort than a dehorning iron. This method is used primarily on intensive ranches where young calves can easily be handled.

Procedures used on older calves with developing horns involve tools of various sizes that scoop or remove the horn below its base and assist in sealing the adjoining blood vessels to reduce bleeding. A cautery tool may also be used at this time to help 
control bleeding from the wound. A local anesthetic should be administered to control pain in older calves undergoing the scoop method. Cattle should be closely monitored for hemorrhage and infection following scoop method.

Larger, well-developed horns of older animals that do not require complete removal can be tipped using a tool that removes the end of the horn to the desired length. If a producer chooses not to remove the horns from purebred cattle, they can be trained into an acceptable shape by using horn weights at the appropriate stage of development.

Implanting. The steroid hormones normally produced by the testes or ovaries are not present at the same concentration in steers or spayed heifers as in intact animals. Because of this, castrated animals can have a slower growth rate. Several hormonal and anabolic ear implants are available for use in beef cattle and are regulated by the FDA. Implants increase weight gain and feed efficiency when cattle also receive adequate nutrition. Also, implants in cattle tend to increase leanness and decrease the fat content of the beef products. Beef products from implanted cattle are safe for consumption. A $3 \mathrm{oz}$. portion of non-implanted beef has about 1.01 nanograms (ng, one-billionth of a gram) of estrogen; implanted beef has $1.85 \mathrm{ng}$. (In comparison, the estrogen content of a single chicken's egg is $1,750 \mathrm{ng}$ and the estrogen content of a glass of cow's milk is $35.5 \mathrm{ng}$.) Implants in the form of small pellets are placed in the back of one ear between the skin and cartilage, following label instructions. At the time of slaughter, the implants are discarded as part of the normal beef slaughter process.

\section{REPRODUCTION MANAGEMENT PRACTICES}

Beef cattle are not seasonal breeders like horses, sheep, and goats, but can reproduce throughout the year. This allows producers in different regions to adjust their breeding program to have cows calve at the most favorable time of the year. Typically, there are fall and spring calving periods, but calving may occur any time. Factors influencing the time of year for calving may include climate and the utilization of available forage late in the nursing calf's growth period.

Puberty. Puberty normally occurs in both bulls and heifers by the time they are 6 to 18 months old. The age of puberty varies greatly due to breed differences as well as environmental factors such as climate and level of nutrition. It is possible for beef cattle to reach sexual maturity and enter the breeding herd as yearlings. Yearling bulls can breed a limited number of heifers or cows. Heifers may be successfully bred as yearlings ( 14 to 16 months of age) to calve for the first time at 2 years of age.

Breeding. Several management practices are used to enhance the reproductive success of the cow herd and produce superior beef cattle. Proper decisions made before breeding can prevent reproductive failures. The animals used for breeding must be physically and physiologically prepared to produce healthy offspring. Considerations also include implementing a preventive health program and supplementing nutrients as required. Selection of bulls with a record of easy calving (known as calving ease) can reduce calving difficulties. Management of young replacement animals to ensure adequate growth before and after the first breeding season and pregnancy is also important. Replacement animals require adequate nutrition to meet the demands of reproduction and lactation while they continue to grow to maturity.

Most commercial cow-calf producers breed their cattle by natural methods but try to maintain a controlled calving season. A calving season of 45 to 60 days provides economic advantages that include higher weaning weights and lower labor costs. In order to achieve a short calving season, breeders place the bulls in cow and heifer pastures for specific time periods, usually 45 to 90 days. Typically, one bull is used to service 25 to 30 cows. This ratio may vary based on pasture topography, feed condi- 
tions, and the age and condition of the bulls. When bulls are not being used for breeding, they require a well-fenced pasture with at least 1 to 2 acres' space per bull (several bulls may be kept in the same pasture). Adequate nutrition is essential to the maintenance of fertile, active bulls. Young bulls less than 4 years of age are often preferred by cow-calf producers because there is less risk that they are carrying Trichomonosis, a venereal disease that can result in poor reproductive performance.

Some producers may elect to use artificial insemination in place of natural breeding. With artificial insemination, a large number of cows can be bred using the semen from a bull that may have greater genetic merit than the bulls available for natural breeding. This can improve the genetic quality or diversity of the herd without necessitating the care of a large number of bulls on the ranch. Artificial insemination may also help eradicate or control the spread of venereal diseases.

Embryo transfer is used primarily by seedstock producers. Fertilized ova are collected from genetically superior cows and transferred to recipient cows that carry the embryos to term. Conception rates with embryo transfer are estimated at 55 to 65 percent.

The reproductive efficiency of the herd and possible health problems affecting the reproductive tract can be evaluated in both cows and bulls. Rectal palpation is a common method for detecting pregnancy in cows, and other techniques such as ultrasound are being developed and used. Scrotal examination and palpation along with the collection and evaluation of semen are used to assess bulls' breeding soundness and fertility. It is important to have appropriate facilities and that only veterinarians or skilled technicians perform these procedures. It also is essential that the breeding cattle be handled quietly and easily to minimize their stress and discomfort.

Gestation. The gestation period for a cow is slightly more than 9 months. Typically, beef cows are bred to calve every 12 months during their productive lives. Beef cows usually remain in full production for 5 to 8 years or more. Bulls remain in service for 2 to 6 years in commercial breeding herds. Superior animals in purebred herds may stay in production longer, depending on their breeding value.

Calving. The birth of a healthy calf is essential for continuation of the beef production cycle. Failure to produce a live calf can occur at any time in the reproductive process. This can be the result of disease, nutrition, or genetic factors that affect the animals' ability to conceive, maintain pregnancy, or successfully deliver a healthy calf. By being knowledgeable about the processes involved in calving, the producer improves his or her capacity to determine whether or when to provide assistance.

Clean, easily observable calving areas should be available for pregnant cows and heifers. Depending on the time of year and the region of the state, shelter may be needed to protect the cow and calf from the elements. Under most California conditions, calving occurs on pastures or rangelands where the cows seek their own location for calving. At calving time, the producer may want to manage first-calf heifers in groups separate from the main cow herd. This will allow for more frequent observation in case the heifers need assistance.

Weaning. As nursing calves grow older, their dams' milk production decreases. Calf weaning allows the cow to build up her body reserves before the birth of her next calf. Weaning can occur at any time from immediately after calving up to near the time of the next calving. Beef calves typically are weaned at 6 to 8 months of age. Weaning ages within a herd may vary from year to year based on forage quality and availability, cow condition, and market prices. Weaning separates the calf from the cow long enough for the cow's lactation to cease. The calf then transitions to a non-milk diet. Weaning is a stressful time for both the cow and the calf: it interrupts and removes the bonding that has existed between them since the calf's birth. 
Weaning does not cause physical pain to the animals, but there are observable indicators of behavioral stress when the calf and its dam are separated. This stress can be managed or reduced in a number of ways. Two methods are commonly used. One is to separate the cows from the calves by removing the cows to a new location far away to prevent either group from hearing or seeing the other. Keep the calves in their original location, where they are familiar with the watering and feeding facilities. Often, cows and calves will bawl for 3 days or more after an abrupt and total separation, and calves may decrease their feed intake and pace fencelines. A less stressful method for both the cows and calves is fenceline weaning, where cows and calves are placed on opposite sides of a strong fenceline to prevent the reuniting of the calf with its dam. Again, keep the calves on the side of the fence they were accustomed to prior to separation. The fenceline weaning method's advantage is that it increases the calves' average daily gain for up to 10 weeks following weaning when compared to the complete separation method. Adequate facilities will be necessary for feeding and watering the calves as well as the dams and for dust control, if necessary.

After weaning, calves usually are grouped by age and gender. Young bulls are separated from steers and non-pregnant heifers. This protects the heifers from untimely pregnancies and the potential for injuries that could result from breeding activity. Yearling bulls are managed separately from older, breeding-age bulls to prevent injury to the younger bulls. Introduction of new bulls, regardless of age, into holding pens or fields occupied by other bulls can disrupt the social order of the bulls and may precipitate injuries from fighting or sexual activity.

\section{TRANSPORTATION}

The transportation of cattle to and from farms, ranches, feedlots, auctions, and sales facilities and to processing facilities is an important, routine operation in beef cattle

production. Proper handling and transportation practices are important for the safety and welfare of the animals being moved. Improper handling and transportation can cause stress, illness, and injury to the cattle.

Cattle are transported in a variety of vehicles, ranging from stock trailers pulled by pick-up trucks to semi-tractors pulling one or two semi-trailers. The trailers may have upper and lower levels, each of which may be divided into several compartments by gates. Commercial livestock transportation companies and producers who transport cattle with their own equipment are regulated by federal and state agencies (for online information, go to www.dot.ca.gov). Regulations include the maximum limits on the length and weight of the vehicles. Normally, stock trailers and small livestock trucks have less carrying capacity than the commercial livestock trucks. However, a semitractor-trailer combination may not be able to navigate narrow roads with sharp turns as easily as other combinations of trucks and trailers.

Proper loading chute design and maintenance are important in preventing injuries and minimizing handling stress while loading cattle. Position the truck as close to the loading chute as possible and use an adjustable loading chute to reduce the potential for injuries. The loading chute's deck should be slip-resistant and the whole chute should be inspected for structural soundness. Loading chute gates should have a mechanism to securely prevent livestock from pushing gates open and cattle possibly escaping or falling from the chute. Regardless of what equipment is used for transportation, cattle should be handled in a way that ensures their safety and welfare through all phases of transport.

In preparation for shipping, separate cattle by weight and gender when possible. Also, if possible, load the separated groups into separate compartments of the truck or trailer. Appropriately sized equipment is important to the prevention of overcrowding 
Table 3. Recommended truck loading densities for cattle without horns; increase the per-animal space by 5 percent for cattle with horns (extrapolated from CARC, 2001)

\begin{tabular}{|cc|}
\hline Weight $(\mathbf{l b})$ & Floor area (sq. ft) \\
\hline 200 & 3.5 \\
300 & 4.9 \\
400 & 6.3 \\
500 & 7.2 \\
600 & 8.5 \\
800 & 10.5 \\
1,000 & 12.4 \\
1,200 & 14.0 \\
1,400 & 15.5 \\
\hline
\end{tabular}

and possible injury or bruising (table 3). Cattle also need adequate space to allow them to stand up again if they should fall or slip during loading, unloading, or transit.

Communication is the key to safely loading cattle into trucks as personnel move the cattle quietly and patiently in order to prevent injuries to the animals. When cattle are given the opportunity, they will follow their instinctual herding urge to move through the alleys and chutes that lead into the truck or trailer. Generally, the appropriate number of cattle to fill a compartment in the trailer is loaded as a single group. Once the first group is loaded, gates to that compartment are secured and ramps may be adjusted to load each of the remaining groups. Exercise care when changing gates and ramps in the trailer to ensure the safety of both the livestock and the livestock handler. Sick or injured cattle require special handling that may include separate loading, transportation, and care to prevent additional stress or injury.

In preparation for moving cattle, a handler should pay particular attention to weather forecasts. Extreme high or low temperatures during transit can be stressful for cattle. The trailer must always receive adequate ventilation. All equipment should be checked before departure to make sure it is mechanically sound. This will help prevent additional stress from prolonged transit time caused by equipment failure. During transit, the ride for the cattle should be as smooth as possible. To help keep cattle from falling, the floors of the trucks and trailers must be slip resistant. Drivers should avoid sudden starts and stops and sharp turns at high speed.

It is important that cattle be transported in the minimum amount of time in order to keep transportation stress to a minimum. Stops during transit should be planned so that the cattle can be checked to ensure that they are well dispersed and standing.

A federal law known as the 28-Hour Rule (Title 49 U.S. Code Section 80502) and portions of the California Food and Agricultural Code (Section 16908) limit the maximum transit period to 28 consecutive hours without unloading the animals for feeding, water, and rest. The maximum period of time allowed for transporting cattle should be determined with consideration for the cattle's fitness to travel, environmental conditions, vehicle design, road conditions, and handling stress.

Upon arrival at their destination, the cattle should be unloaded quietly. Cattle have a tendency to rush from a vehicle, so additional care must be taken to ensure that they unload evenly and slowly. Once they are unloaded, the cattle should be checked for injury or sickness. Supplementary care and handling should be provided for any sick or injured cattle.

After a long haul, fatigued animals should be rested and provided access to feed and water before they are processed or released into pastures. Shrink, the loss of body weight from excretory losses in manure and urine without intake of feed or water, may have occurred during transit when cattle were stressed for a short period of time. Temporary losses of 3 to 10 percent or more of the animal's body weight can be attributable to shrink losses during transit. Cattle that have experienced additional stress and fasting conditions during prolonged transport may exhibit body weight losses in excess of 10 percent. This degree of shrink may cause serious health problems, and affected cattle should be monitored by a veterinarian. 


\section{CONCLUSION}

The cattle production practices described in this publication are commonly used in California. The authors consider these practices to be both appropriate and practical. The most appropriate practices will vary and each cattle producer must consider numerous factors before deciding which are the best practices for his or her operation. Often, producers make compromises in some areas in order to achieve a greater overall benefit. New research involving beef cattle production practices and techniques to improve efficiency of production, minimize stress, and enhance livestock well-being is ongoing at many universities, private companies, and production units throughout the United States.

When new information is developed, beef producers have the responsibility to evaluate which management practices to incorporate into their production systems. Those decisions should be based on sound professional judgment, scientific data, training, and experience in the safe, humane, and efficient production of beef. Beef cattle production in California not only provides a wholesome agricultural product, it also contributes to the management of much of California's open space land and watersheds.

\section{SELECTED REFERENCES}

AABP Animal Welfare Committee. 1999. Practical euthanasia in cattle: Considerations for the producer, livestock market operator, livestock transporter, and veterinarian. Rome, GA: American Association of Bovine Practitioners. Available online at http://www.aabp.org/resources/euth.pdf

Albright, J. L., and C. W. Arave. 1997. The behavior of cattle. New York: CAB International.

Bath, D. L., J. R. Dunbar, J. M. King, S. L. Berry, R. O. Leonard, and S. E. Olbrich. 1989. By-products and unusual feedstuffs. Feedstuffs 61(31):32-37.

California Cattlemen's Association. 1994. Cow calf quality assurance program: Producer's handbook and instructor's manual. Sacramento: California Cattlemen's Association.

California Department of Food and Agriculture. 2006. California agriculture resource directory, 2005. Available online at http://www.cdfa.ca.gov/card/pdfs/ 5cdfalivestock.pdf

Canadian Agri-Food Research Council (CARC). 2001. Recommended code of practice for the care and handling of farm animals: Transportation. Nepean, Ontario: Canadian Food Inspection Agency. Available online at http://www.inspection.gc.ca/english/anima/heasan/transport/transporte.shtml

CAST (Council for Agricultural Science and Technology). 1985. Antibiotics for animals. Ames: Iowa State University, Council for Agricultural Science and Technology.

Collier, R. J., D. K. Beede, W. W. Thatcher, L. A. Israel, and C. J. Wilcox. 1982. Influences of environment and its modification on dairy animal health and production. Journal of Dairy Science 65(11):2213-2227.

Daley, C. A., A. Abbott, P. Doyle, G. Nader, and S. Larson. 2006. A literature review of the value-added nutrients found in grass-fed beef products. Available online at http://www.csuchico.edu/agr/grassfedbeef/health-benefits/index.html

Drake, D. J., and R. L. Phillips. 2006. Fundamentals of beef management. Oakland: University of California, Division of Agriculture and Natural Resources. Publication 3495. Available via online catalog: http://anrcatalog.ucdavis.edu 
Federation of Animal Sciences. 1999. Guide for the care and use of agricultural animals in agricultural research and teaching, lst revised edition. Savoy, IL: Federation of Animal Science Societies. Pp. 29-36.

Fraser, A. F. 1985. In: Ethology of farm animals. New York: Elsevier. Pp. 83-108, 183-275.

Gebremedhin, K. G., and B. X. Wu. 2001. A model of evaporative cooling of wet skin surface and fur layer. Journal of Thermal Biology 26(6):537-545.

Grandin, T. 1993. Livestock handling and transport. Wallingford, UK: CAB International.

Hurnik, F. 1991. Recommended code of practice for the care and handling of beef cattle. Ottawa: Communication Branch, Agriculture Canada. Available online at http://www.cattle.ca/producer/environment/1RecCodeOfPracticeBeefCattle.pdf

Hutson, G. D. 1985. The influence of barley food rewards on sheep movement through a handling system. Applied Animal Behaviour Science 14:263-273.

Igono, M. O., H. D. Johnson, B. J. Steevens, G. F. Krause, and M. D. Shanklin. 1987. Physiological, productive, and economic benefits of shade, spray, and fan system versus shade of Holstein cows during summer heat. Journal of Dairy Science 70(5):1069-1079.

Jensen, W., and J. Oltjen. 1992. Beef care practices. Davis: University of California, Cooperative Extension. Available online at http://www.vetmed.ucdavis.edu/ vetext/INF-BE_CarePrax.html

Kaneko, J. J. 1980. Clinical biochemistry of domestic animals, 3rd edition. San Francisco: Academic Press. Appendix VI.

Keister, Z. O., K. D. Moss, H. M. Zhang, T. Teegerstrom, R. A. Edling, R. J. Collier, and R. L. Ax. 2002. Physiological responses in thermal stressed Jersey cows subjected to different management strategies. Journal of Dairy Science 85:3217-3224.

Livestock Conservation Institute. 1992. Livestock trucking guide. Available online at http://www.animalagriculture.org/Ed_resources/Pamphlets/Livestock\%20 Trucking\%20Guide.pdf or http://www.animalagriculture.org/Ed_resources/ Pamphlets/pamphlets.asp

Mathis, C. P., J. E. Sawyer, and R. Parker. 2002. Managing and feeding beef cows using body condition scores. Las Cruces: New Mexico State University, Cooperative Extension Service. Circular 575. Available online at http://www. cahe.nmsu.edu/pubs/_circulars/CR575.pdf

Mitlöhner, F. M., M. L. Galyean, and J. J. McGlone. 2002. Shade effects on performance, carcass traits, physiology, and behavior of heat-stressed feedlot heifers. Journal of Animal Science 80(8):2043-2050.

Muller, C. J. C., and J. A. Botha. 1994. Effect of shade on various parameters of Friesian cows in a Mediterranean climate in South Africa. 2. Physiological responses. Journal of Animal Science (South Africa) 24(2):56-60.

National Research Council. 2000. Nutrient requirements of beef cattle, 7 th edition. Washington, DC: National Academies Press.

Oltjen, J. W., A. C. Bywater, C. R. Benson, and J. W. Clawson. 1982. An analysis of the California beef industry. Oakland: University of California, Division of Agriculture and Natural Resources. Publication 3281. Available via online catalog: http://anrcatalog.ucdavis.edu 
Price, E. O., J. E. Harris, R. E. Borgwardt, M. L. Sween, and J. M. Connor. 2003. Fenceline contact of beef calves with their dams at weaning reduced the negative effects of separation behavior and growth rates. Journal of Animal Science 81:116-121.

State Humane Association of California. 2005. California laws handbook. Pacific Grove: State Humane Association of California.

Stull, C. L., S. L. Berry, B. A. Reed, and M. A. Payne. 2004. Dairy welfare evaluation guide. Davis: University of California, Cooperative Extension. Available online at http://cdqa.org/ahw/index.htm

Van Reit, W. J. 1980. Beef production in California. Oakland: University of California, Division of Agriculture and Natural Resources. Leaflet 21184. Available via online catalog: http://anrcatalog.ucdavis.edu

Webster, A. J. F. 1983. Environmental stress and the physiology, performance, and health of ruminants. Journal of Animal Science 57(6):1584-1593.

West, J. W., B. G. Mullinix, and J. K. Bernard. 2003. Effects of hot, humid weather on milk temperature, dry matter intake, and milk yield of lactating dairy cows. Journal of Dairy Science 86:232-242.

Western Beef Resource Committee. 2006. Cow-calf management guide and cattle producer's library. Moscow, ID: University of Idaho, Department of Animal and Veterinary Science (P. O. Box 44233, Moscow, ID ). Available via online catalog: http://www.avs.uidaho.edu/wbrc/

\section{APPENDIX}

\section{Description of the body condition scoring system}

(Reprinted with permission from Mathis, Sawyer, and Parker, 2002)

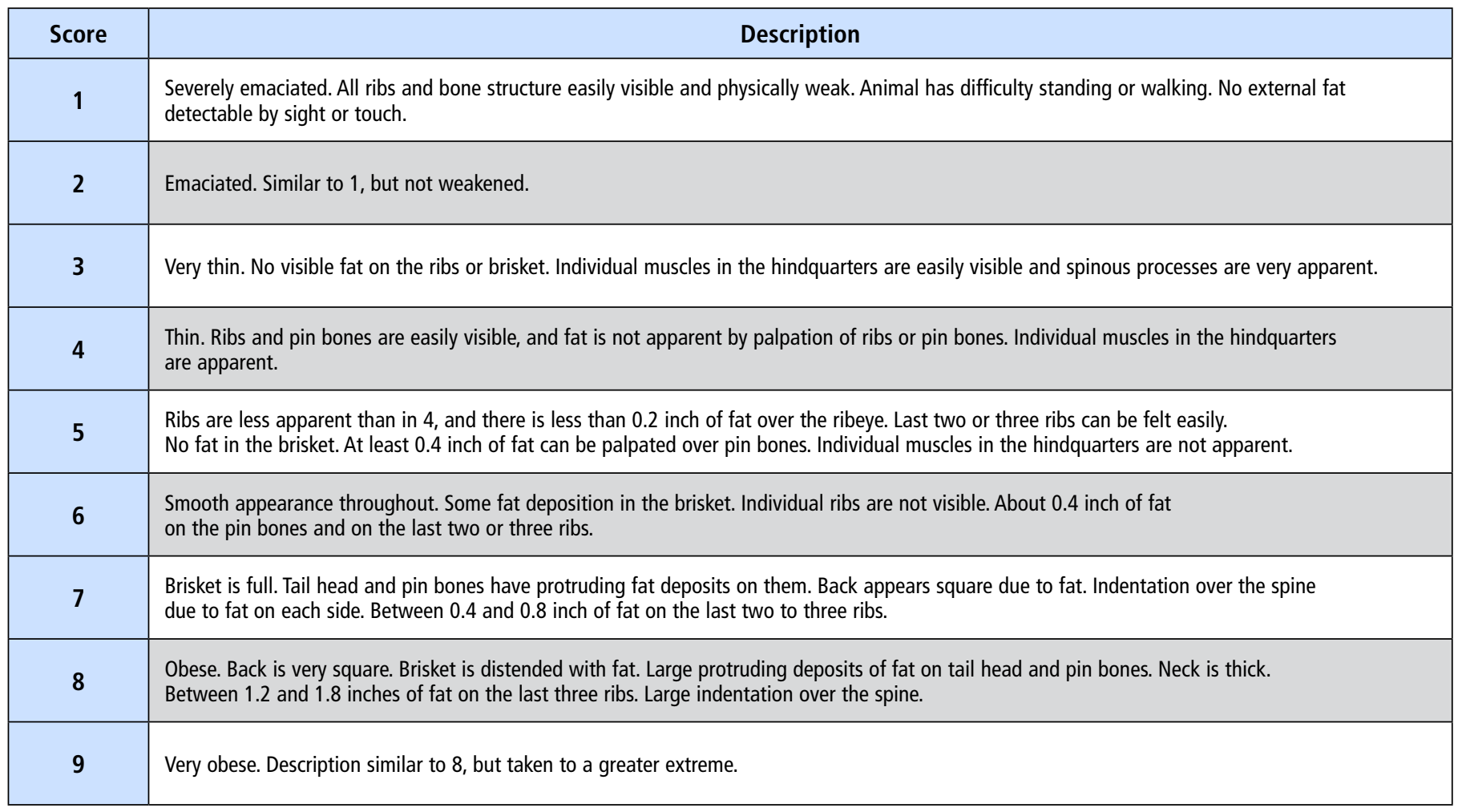




\section{GLOSSARY}

Abort: To terminate the pregnancy.

Body condition: The body reserves (body fat) of an animal at specific stages of its production cycle.

Breed: A group of animals that have a common origin and similar genetic characteristics that distinguish them from other groups within the same species.

Bull: An uncastrated male bovine of any age.

Calf: A young bovine of either sex under the age of one year.

Castrate: To surgically remove the testicles or ovaries or to cause the testicles to become nonfunctional.

Colostrum: The milk containing maternal antibodies produced by the cow prior to calving and during the first few days after calving.

Confinement: A practice of confining cattle for a specific period during production, for instance using feedlots rather than grazing cattle on rangelands or pasture.

Cow: A female bovine that has produced one or more calves.

Crossbreeding: A system of breeding that combines two or more breeds.

Cull: To remove less productive or undesirable cattle from a herd.

Dam: The female parent of a calf.

Energy: The component of a feed ration that gives animals the ability to grow, lactate, reproduce, and maintain themselves physically.

Environment: All conditions of production, including feeding, housing, management, and climate, that affect the life and performance of cattle, exclusive of their genetics.

Estrous cycle: The reproductive cycle of a cow.

Feeder cattle: Cattle in feedlots.

Feedlot: A confinement facility where cattle are fed.

Fertility: All factors affecting conception and reproduction.

Gestation: The period of time between conception and calving.

Heifer: A young female bovine that has not produced a calf.

Morbidity: The incidence of disease.

Mortality: The number of deaths.

Necropsy: An examination of an animal after death for determining cause of death.

Nutrients: The chemical substances found in feed that are necessary for the maintenance, production, and health of animals.

Parasite: An organism that nourishes itself by feeding on host animals.

Particulate matter (PM): A class of air pollutant, consisting of a combination of small particles from a variety of sources, that may detrimentally affect health.

Parturition: The act of giving birth; calving.

Polled cattle: Naturally hornless cattle; having no horns or scurs. 
Processing: The act of administering a specific production or management practice or a series of production or management practices to an animal.

Roughage: Feeds high in fiber content and low in energy and protein digestibility.

Rumen: The first and largest of the four compartments of the bovine stomach, where microbial fermentation of feed occurs.

Ruminant: An animal, such as a cow, that ruminates and digests cellulose.

Ruminate: To regurgitate and re-masticate roughages.

Shrink: The loss of body weight from excretory losses in manure and urine without intake of feed or water.

Sire: The male parent of a calf.

Squeeze chute: An adjustable restraint device used to safely catch and confine an animal during processing.

Steer: A male bovine castrated before the development of secondary sexual characteristics.

Stockers: Weaned calves that graze forage or are fed roughages until they enter a feedlot.

Wean: To permanently remove of a calf from its dam.

\section{AUTHORS' NOTE}

Beef Care Practices is one of a series of publications addressing the issue of animal care as it relates to food animal production in California. This is the second edition of Beef Care Practices: the first edition was is listed as Jensen and Oltjen (1992) in Selected References, above. This revised publication is the result of a joint project between the University of California Cooperative Extension (UCCE), beef industry representatives, and members of the UC Agriculture and Natural Resources (ANR) Beef and Range Workgroup.

Technical editors for the publication are Carolyn Stull, Animal Welfare Specialist, Veterinary Medicine Cooperative Extension, UC Davis; Sheila Barry, UCCE Bay Area Natural Resource Advisor in Santa Clara and Contra Costa Counties; and Wayne Jensen, UCCE Livestock Advisor in Santa Barbara and San Luis Obispo Counties.

Besides the technical editors, contributing authors include Dan Drake, UCCE Livestock Advisor, Siskiyou County; Larry Forero, UCCE Livestock Advisor, Shasta County; Juan Guerrero, UCCE Area Livestock Advisor, Imperial and Riverside Counties; John Maas, Beef Cattle Extension Veterinarian, School of Veterinary Medicine, UC Davis; Frank Mitloehner, Air Quality Specialist, Animal Science Department, UC Davis; Glenn Nader, UCCE Livestock Advisor, Butte, Sutter, and Yuba Counties; and Jim Oltjen, Animal Management Specialist, Animal Science Department, UC Davis. 
METRIC CONVERSIONS

\begin{tabular}{|c|c|c|c|}
\hline English & $\begin{array}{l}\text { Conversion factor for } \\
\text { English to Metric }\end{array}$ & $\begin{array}{l}\text { Conversion factor for } \\
\text { Metric to English }\end{array}$ & Metric \\
\hline \multicolumn{4}{|l|}{ Length } \\
\hline $\begin{array}{l}\text { inch (in) } \\
\text { foot (ft) } \\
\text { yard (yd) }\end{array}$ & $\begin{array}{l}\times 2.54 \\
\times 0.3048 \\
\times 0.914\end{array}$ & $\begin{array}{l}\times 0.394 \\
\times 3.28 \\
\times 1.09\end{array}$ & $\begin{array}{l}\text { centimeter }(\mathrm{cm}) \\
\text { meter }(\mathrm{m}) \\
\text { meter }(\mathrm{m})\end{array}$ \\
\hline \multicolumn{4}{|l|}{ Area } \\
\hline $\begin{array}{l}\text { acre (ac) } \\
\text { square foot (sq. ft) }\end{array}$ & $\begin{array}{r}\times 0.4047 \\
\times 0.0929\end{array}$ & $\begin{array}{l}\times 2.47 \\
\times 10.764\end{array}$ & $\begin{array}{l}\text { hectare (ha) } \\
\text { square meter (m2) }\end{array}$ \\
\hline \multicolumn{4}{|l|}{ Volume } \\
\hline $\begin{array}{l}\text { gallon (gal) } \\
\text { gallon per acre }\end{array}$ & $\begin{array}{l}\times 3.785 \\
\times 9.36 \\
\end{array}$ & $\begin{array}{l}\times 0.26 \\
\times 0.106\end{array}$ & $\begin{array}{l}\text { liter }(\mathrm{L}) \\
\text { liter per hectare (L/ha) }\end{array}$ \\
\hline \multicolumn{4}{|l|}{ Mass } \\
\hline $\begin{array}{l}\text { pound }(\mathrm{lb}) \\
\text { pound per acre (lb/ac) }\end{array}$ & $\begin{array}{l}\times 0.454 \\
\times 1.12 \\
\end{array}$ & $\begin{array}{l}\times 2.205 \\
\times 0.89 \\
\end{array}$ & $\begin{array}{l}\text { kilogram }(\mathrm{kg}) \\
\text { kilogram per hectare }(\mathrm{kg} / \mathrm{ha})\end{array}$ \\
\hline \multicolumn{4}{|l|}{ Temperature } \\
\hline Fahrenheit ( $\left.{ }^{\circ} \mathrm{F}\right)$ & ${ }^{\circ} \mathrm{F}=\left({ }^{\circ} \mathrm{C} \times 1.8\right)+32$ & ${ }^{\circ} \mathrm{C}=\left({ }^{\circ} \mathrm{F}-32\right) \div 1.8$ & Celsius $\left({ }^{\circ} \mathrm{C}\right)$ \\
\hline
\end{tabular}

\section{FOR MORE INFORMATION}

You will find related information in these titles and in other publications, slide sets, CD-ROMs, and videos from UC ANR:

Beef Animal Health: What You Need to Know about Animal Drugs, DVD 6563D

Fundamentals of Beef Management, Publication 3495

Understanding and Improving Beef Cattle Carcass Quality, Publication 8130

To order these products, visit our online catalog at http://anrcatalog.ucdavis.edu. You can also place orders by mail, phone, or FAX, or request a printed catalog of publications, slide sets, CD-ROMs, and videos from

University of California

Agriculture and Natural Resources

Communication Services

6701 San Pablo Avenue, 2nd Floor

Oakland, California 94608-1239

Telephone: (800) 994-8849 or (510) 642-2431

FAX: (510) 643-5470

E-mail inquiries: danrcs@ucdavis.edu

An electronic version of this publication is available on the ANR Communication Services Web site at http://anrcatalog.ucdavis.edu.

Publication 8257

ISBN-13: 978-1-60107-477-5

This publication has been anonymously peer reviewed for technical accuracy by University of California scientists and other qualified professionals. This review process was managed by the ANR Associate Editor for Animal, Avian, Aquaculture, and Veterinary Sciences.

C)2007 by the Regents of the University of California Division of Agriculture and Natural Resources. All rights reserved. 
To simplify information, trade names of products have been used. No endorsement of named products is intended, nor is criticism implied of similar products that are not mentioned.

The University of California prohibits discrimination or harassment of any person on the basis of race, color, national origin, religion, sex, gender identity, pregnancy (including childbirth, and medical conditions related to pregnancy or childbirth), physical or mental disability, medical condition (cancer-related or genetic characteristics), ancestry, marital status, age, sexual orientation, citizenship, or status as a covered veteran (covered veterans are special disabled veterans, recently separated veterans, Vietnam era veterans, or any other veterans who served on active duty during a war or in a campaign or expedition for which a campaign badge has been authorized) in any of its programs or activities.

University policy is intended to be consistent with the provisions of applicable State and Federal laws.

Inquiries regarding the University's nondiscrimination policies may be directed to the Affirmative Action/Staff Personnel Services Director, University of California, Agriculture and Natural Resources, 1111 Franklin Street, $6^{\text {th }}$ Floor, Oakland, CA 94607, (510) 987-0096. For information about obtaining this publication, call (800) 994-8849. For downloading information, call (530) 297-4445.

pr-6/07-WJC/RW 